


\section{Are All Single Atoms Created Equal? Surface Density Dependent Catalytic Activity of Single Pd Atoms Supported on Ceria}

Yongseon Kim ${ }^{1, \|}$, Greg Collinge ${ }^{2,3, \|}$, Mal-Soon Lee ${ }^{2,3}$, Konstantin Khivantsev ${ }^{3}$, Sung June $\mathrm{Cho}^{4, *}$, Vassiliki-Alexandra Glezakou ${ }^{2,3}$, Roger Rousseau ${ }^{2,3, *}$, Janos Szanyi ${ }^{3, *}$, Ja Hun Kwak $^{1, *}$

${ }^{1}$ Department of Chemical Engineering, Ulsan National Institute of Science and Technology (UNIST), 50 UNIST-gil, Ulsan 44919, Republic of Korea

102 Physical and Computational Sciences Directorate and Institute for Integrated Catalysis, Pacific Northwest National Laboratory, Richland, WA 99354, USA

${ }^{3}$ Institute for Integrated Catalysis, Pacific Northwest National Laboratory, Richland, WA 99352 USA

${ }^{4}$ Department of Chemical Engineering, Chonnam National University, 77 Yongbong-ro, Buk-

15 gu, Gwangju 61186, Republic of Korea

*Corresponding authors: sjcho@jnu.ac.kr, roger.rousseau@pnnl.gov, janos.szanyi@pnnl.gov, jhkwak@unist.ac.kr

$20 \quad$ II These authors contributed equally. 


\begin{abstract}
The analogy between single atom catalysts (SACs) and molecular catalysts predicts that the specific catalytic activity of these systems is constant. We provide evidence that this prediction is not necessarily true. As a case in point, we show that the specific activity over ceriasupported single Pd atoms linearly increases with metal atom density, originating from the cumulative enhancement of lattice oxygen mobility. The long-range electrostatic fingerprints $(\sim 1.5 \mathrm{~nm})$ around each $\mathrm{Pd}$ site overlap with each other as surface Pd density increases, resulting in the observed deviation from constant specific activity. These cooperative effects exhaust previously active $\mathrm{O}$ atoms above a certain $\mathrm{Pd}$ density, leading to their permanent 10 removal and consequent drop in reaction rate. The findings of our combined experimental and computational study show that the specific catalytic activity of reducible oxide-supported single atom catalysts can be tuned by varying the surface density of single metal atoms.
\end{abstract}




\section{MAIN}

Supported single atom catalysts (SACs) have attracted considerable attention owing to their unique activity, efficient utilization of supported noble metals, and potentially bridging the gap between homogeneous and heterogeneous catalysis. ${ }^{1-4}$ Increasing the surface metal density of SACs is commonly sought after to increase the mass activity of industrial catalysts. ${ }^{5-10}$ However, such efforts assume that the active sites of SACs exhibit constant specific activity. ${ }^{1,11-13}$ Here, using $\mathrm{CO}$ oxidation as a probe reaction, we show that, the specific activity of $\mathrm{Pd} / \mathrm{CeO}_{2}$ SACs increases with $\mathrm{Pd}$ density due to synergistic nonlocal effects. This phenomenon, however, is support-dependent as $\mathrm{Pd}$ SACs supported on non-reducible $\gamma-\mathrm{Al}_{2} \mathrm{O}_{3}$ exhibit constant specific activity for CO oxidation.

Numerous SACs have been characterized and reported to exhibit high activity for the CO oxidation reaction including the seminal $\mathrm{Pt} / \mathrm{FeO}_{\mathrm{x}}$ catalyst. ${ }^{14}$ The charge state of the single atom centers is commonly invoked to explain this activity, ${ }^{15}$ reportedly enhancing $\mathrm{CO}$ and/or $\mathrm{O}_{2}$ adsorption. Subsequently, the choice of support and its redox state has been shown to impact $\mathrm{CO}$ oxidation activity greatly, ${ }^{16,17}$ with irreducible supports, such as $\gamma-\mathrm{Al}_{2} \mathrm{O}_{3}$ or $\mathrm{MgO}$, identified as comparatively inactive ${ }^{18}$ or unstable ${ }^{19-21}$ without modification such as the induction of defect sites ${ }^{22}$ or the addition of $\mathrm{La}^{23}$ or other heteroatom substituents. ${ }^{24}$ Conversely, single atoms on reducible supports show considerable CO oxidation activity. ${ }^{25-27}$ Some supports have even been reported to allow the stabilization of metallic single atoms. ${ }^{28}$ Spezzati et al. reported high CO-oxidation activity of isolated $\mathrm{Pd}$ atoms supported on $\mathrm{CeO}_{2}(111)$ and identified a $\mathrm{PdO}_{x}$ species as the active site. ${ }^{29,30}$ However, despite considerable research efforts on SACs, the effect of surface density of single metal atoms on catalytic activity has not been elucidated.

In this study, we report the synergistic effect between single $\mathrm{Pd}$ atoms supported on $\mathrm{CeO}_{2}$.

$25 \mathrm{H}_{2}$-temperatrue programmed reduction (TPR) and in-situ Raman studies employed in this work clearly show that the reducibility of the support is enhanced as the density of single Pd atoms increases. Density functional theory (DFT) calculations confirm the lowering in oxygen vacancy formation energies as the surface $\mathrm{Pd}$ density increases, while $\mathrm{CO}$ and $\mathrm{O}_{2}$ adsorption 
energies remain unaffected. This suggests that the observed specific activity trends are due to the activation of lattice $\mathrm{O}$ by $\mathrm{Pd}$. Charge and spin density analysis allow us to identify the active site as an overoxidized $\mathrm{Pd}^{2+}$ in a $\left[\mathrm{PdO}_{4}\right]$ square planar complex consistent with $\mathrm{X}$-ray Adsorption Spectroscopy (XAS). The Pd atom is overoxidized, past +2 , and its coordinating oxygens are valence unsaturated, making $\left[\mathrm{PdO}_{4}\right]$ an excellent oxidizer with a considerableand importantly, cumulative, range of effect. Thus, as the surface density of $\left[\mathrm{PdO}_{4}\right]$ complexes increases, their individual oxidation power also increases. The support mediates this process, allowing for the shuttling of excess charge to nearby $\left[\mathrm{PdO}_{4}\right]$, explaining why $\gamma-\mathrm{Al}_{2} \mathrm{O}_{3}$, a nonreducible support, does not exhibit the same synergy.

10

\section{RESULTS}

\section{CO oxidation on $\mathrm{Pd} / \mathrm{CeO}_{2}$}

The effect of surface single atom density on the catalytic properties of $\mathrm{Pd} / \mathrm{CeO}_{2}$ (see Figure $\mathrm{S} 1$ - S3 for characterization of $\mathrm{CeO}_{2}$ ) and $\mathrm{Pd} / \mathrm{Al}_{2} \mathrm{O}_{3}$ catalysts was investigated in the model reaction of $\mathrm{CO}$ oxidation as a function of surface Pd density, displayed in Figure 1(a) (Figure S4(a) shows the relationship as a function of Pd weight loading).
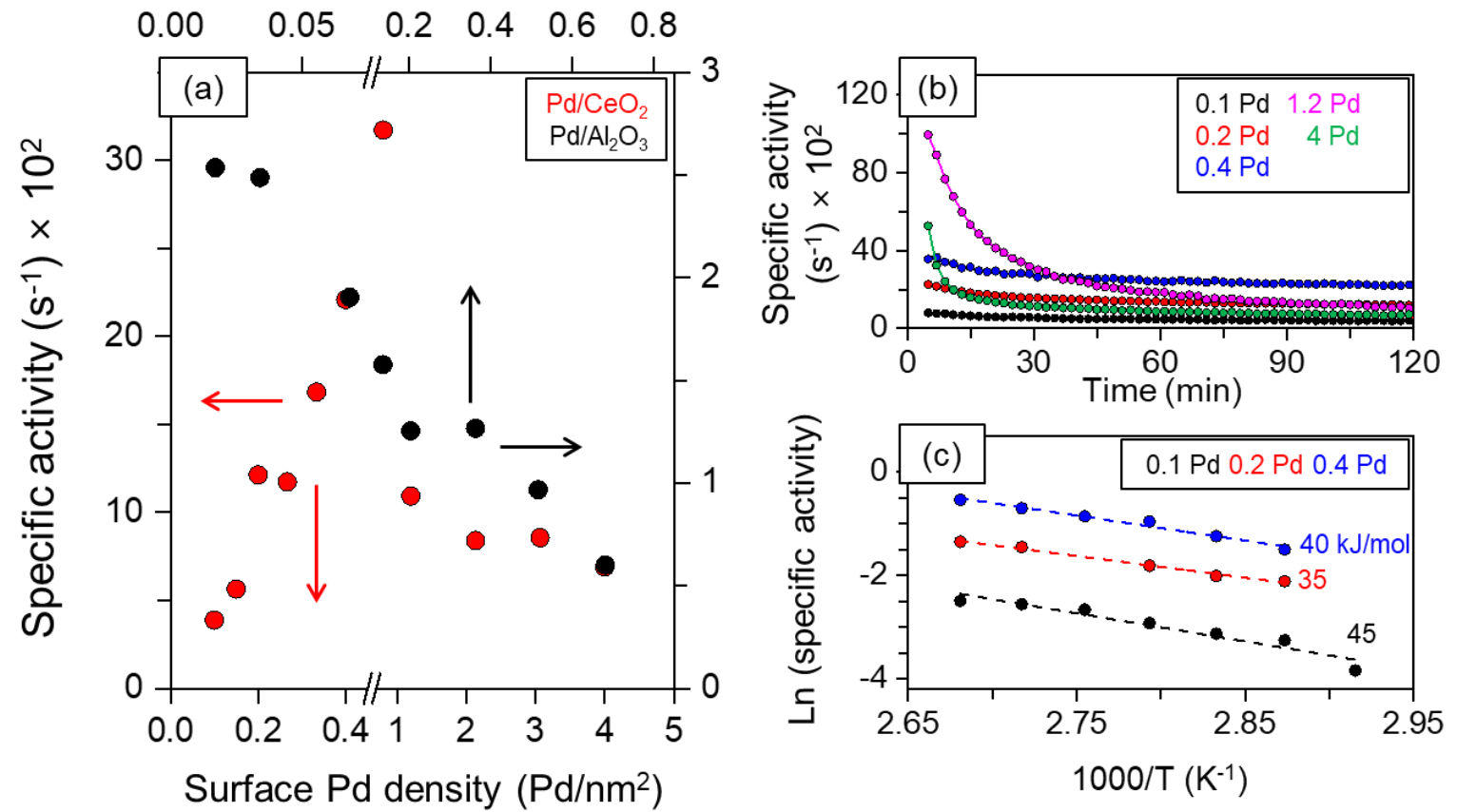
Figure 1. (a) Specific activity of $\mathrm{CO}$ oxidation at steady state as a function of surface Pd density of $\mathrm{Pd} / \mathrm{CeO}_{2}$ and $\mathrm{Pd} / \mathrm{Al}_{2} \mathrm{O}_{3}$. (b) Specific activity of $\mathrm{Pd} / \mathrm{CeO}_{2}$ as function of time. (c) Arrhenius plots of 0.1 , 0.2 and $0.4 \mathrm{Pd} / \mathrm{CeO}_{2}$ catalysts for $\mathrm{CO}$ oxidation.

The specific activity of $\mathrm{Pd} / \mathrm{CeO}_{2}$ catalysts increased linearly with surface $\mathrm{Pd}$ density up to $\sim 0.8 \mathrm{Pd} / \mathrm{nm}^{2}$. This behavior was observed for both initial (Figure S4(b)) and steady state activities (Figure 1(a)). In the contrasting case of $\mathrm{Pd} / \mathrm{Al}_{2} \mathrm{O}_{3}$ catalysts, the specific activity was constant below $\sim 0.034 \mathrm{Pd} / \mathrm{nm}^{2}$, in agreement with previously reported results. ${ }^{1,11,12}$ Specific activity as a function of time for a selected series of $\mathrm{Pd} / \mathrm{CeO}_{2}$ catalysts is also shown in Figure 1(b), (for the entire series of $\mathrm{Pd} / \mathrm{CeO}_{2}$ and $\mathrm{Pd} / \mathrm{Al}_{2} \mathrm{O}_{3}$ catalysts, see Figure $\mathrm{S} 4(\mathrm{c})$ and (d)). $\mathrm{Pd} / \mathrm{CeO}_{2}$ catalysts with $\mathrm{Pd}$ surface densities in the range of $0.1-0.8 \mathrm{Pd} / \mathrm{nm}^{2}$ deactivated slowly while catalysts with surface densities between 1.2-4 Pd/nm² underwent rapid deactivation. Sintering of $\mathrm{Pd}$ atoms/small metal clusters and, as we will show, the permanent removal of previously catalytically active lattice $\mathrm{O}$ atoms are primarily responsible for this activity loss. The apparent activation energies for $\mathrm{Pd} / \mathrm{CeO}_{2}$ catalysts with $\mathrm{Pd}$ surface densities of $0.1,0.2$ and $0.4 \mathrm{Pd} / \mathrm{nm}^{2}$, estimated from Arrhenius plots in Figure $1(\mathrm{c})$, were 45,35 and $40 \mathrm{~kJ} / \mathrm{mol}$, respectively. These values are consistent with a Mars-van Krevelen (MvK) mechanism. ${ }^{31-35}$

Aberration-corrected high angle annular dark field scanning transmission microscopy (ACHAADF-STEM) imaging was used to visualize $\mathrm{Pd}$ atoms/particles in the $\mathrm{CeO}_{2}$ and $\mathrm{Al}_{2} \mathrm{O}_{3}$ supported catalysts (Figures S5 and S6). Due to low z-contrast between $\mathrm{Pd}(\mathrm{z}=46)$ and $\mathrm{Ce}$

$20 \quad(z=58)$, we could not observe single $\mathrm{Pd}$ atoms in $\mathrm{Pd} / \mathrm{CeO}_{2}$ samples with $\mathrm{Pd}$ loading $\leq 0.8$ $\mathrm{Pd} / \mathrm{nm}^{2} .{ }^{36-38}$ On $4 \mathrm{Pd} / \mathrm{CeO}_{2}, \mathrm{Pd}$ nanoparticles were observed despite the poor contrast, implying their absence in the lower $\mathrm{Pd}$ density sample. For $0.034 \mathrm{Pd} / \mathrm{Al}_{2} \mathrm{O}_{3}$, despite the higher z-contrast between $\mathrm{Pd}$ and $\mathrm{Al}$, no $\mathrm{Pd}$ nanoparticles were observed, indicating that $\mathrm{Pd}$ is atomically dispersed. At higher $\mathrm{Pd}$ surface densities (e.g., $0.20 \mathrm{Pd} / \mathrm{Al}_{2} \mathrm{O}_{3}$ ) distinctive $\mathrm{Pd}$ 25 nanoparticles were observed.

Since we could not directly confirm the presence of atomically dispersed $\mathrm{Pd}$ on $\mathrm{CeO}_{2}$, additional structural analysis was carried out. Pd K-edge X-ray Adsorption Near Edge Spectra 
(XANES) (Figure S7) and extended x-ray absorption fine structure (EXAFS) data (Figure S8) were further used to estimate structural parameters (Table 1). The Fourier transformed EXAFS spectra show primarily a Pd-O scattering at $1.99 \AA$ with coordination number of $3.8 \pm 0.6$ and 3.7 \pm 0.5 for 0.8 and $4 \mathrm{Pd} / \mathrm{CeO}_{2}$, respectively. In bulk $\mathrm{PdO}, \mathrm{Pd}-\mathrm{Pd}$ scattering appears around 3.06 and $3.45 \AA$ A with 4 and 8 coordination number, respectively. ${ }^{39}$ However, no Pd-Pd bond was observed in either 0.8 or $4 \mathrm{Pd} / \mathrm{CeO}_{2}$ samples. Interestingly, the corresponding XANES is shifted relative to that of $\mathrm{PdO}$, indicating $\mathrm{Pd}$ to be in an oxidation state greater than $2+$. These results suggest that $\mathrm{Pd}$ is highly dispersed with $\mathrm{Pd}-\mathrm{O}$ coordination number around 4 in an overoxidized charge state.

Table 1. Structural parameters from Pd K-edge EXAFS analysis for 0.8 and $4 \mathrm{Pd} / \mathrm{CeO}_{2}$. (a)

\begin{tabular}{|c|c|c|c|c|c|c|}
\hline Sample & Pair & $\mathbf{C N}^{(\mathbf{b})}$ & Bond distance $(\mathbf{A})$ & $\sigma^{2}\left(\mathbf{p m}^{2}\right)^{(\mathbf{c})}$ & $\Delta \mathrm{E}(\mathbf{e V})^{(\mathbf{d})}$ & $\begin{array}{c}\text { R-factor } \\
(\%)\end{array}$ \\
\hline $0.8 \mathrm{Pd} / \mathrm{CeO}_{2}$ & $\mathrm{Pd}-\mathrm{O}$ & $3.8 \pm 0.6$ & $1.99 \pm 0.02$ & $52 \pm 11$ & $4.9 \pm 2.5$ & 3.0 \\
\hline $4 \mathrm{Pd} / \mathrm{CeO}_{2}$ & $\mathrm{Pd}-\mathrm{O}$ & $3.7 \pm 0.5$ & $1.99 \pm 0.01$ & $11 \pm 18$ & $4.3 \pm 102$ & 1.3 \\
\hline
\end{tabular}

(a) Many-body reduction factor, S02 was set to 0.86 . The number of the free fitting parameter for XAFS data, 11 was always less than the number of independent points given by the Nyquist theorem.

(b) Coordination number, (c) The Debye-Waller factor and (d) Energy shift

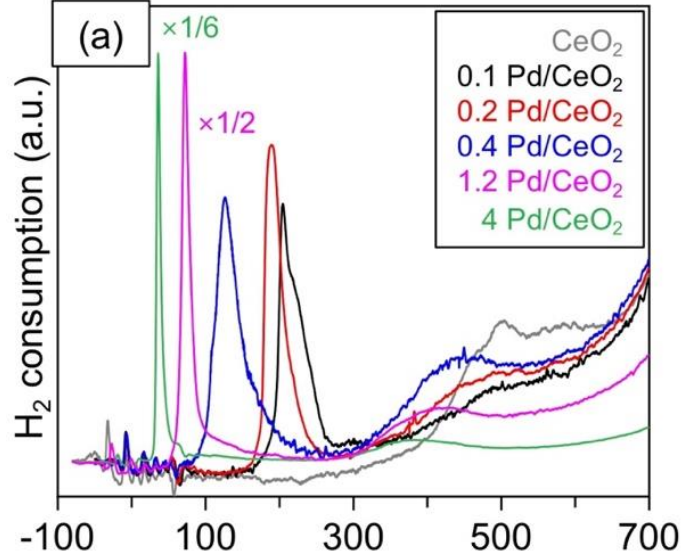

Temperature $\left({ }^{\circ} \mathrm{C}\right)$

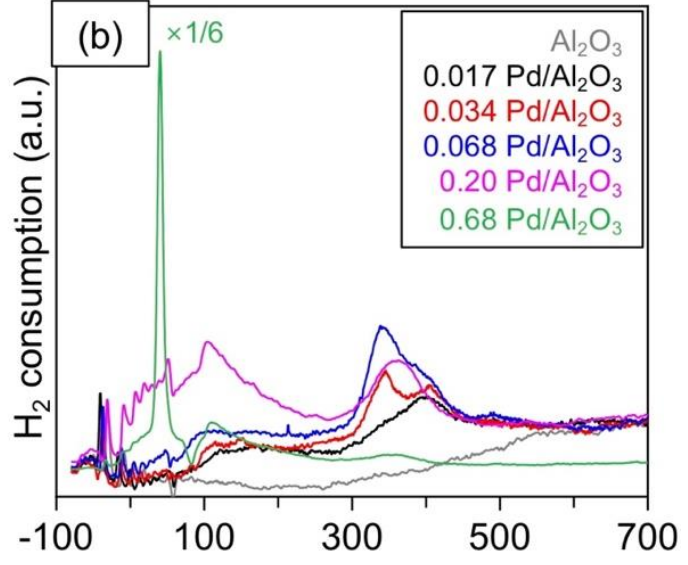

Temperature $\left({ }^{\circ} \mathrm{C}\right)$

Figure 2. $\mathrm{H}_{2}$-TPR profiles of (a) $\mathrm{Pd} / \mathrm{CeO}_{2}\left(m_{\text {cat }}=0.05 \mathrm{~g}\right)$ and $(\mathrm{b}) \mathrm{Pd} / \mathrm{Al}_{2} \mathrm{O}_{3}\left(\mathrm{~m}_{\text {cat }}=0.1 \mathrm{~g}\right)$. The same scale of $y$-axis is used for the figures.

Since $\mathrm{CeO}_{2}$-based $\mathrm{CO}$ oxidation catalysts follow the MvK mechanism, ${ }^{35,40-44}$ the activity must be related with the redox properties of catalysts. To gain information about this, we conducted $\mathrm{H}_{2}$-TPR, see Figure 2(a) and (b) for $\mathrm{Pd} / \mathrm{CeO}_{2}$ and $\mathrm{Pd} / \mathrm{Al}_{2} \mathrm{O}_{3}$ catalysts, respectively. 
On bare $\mathrm{CeO}_{2}$, surface and bulk reduction peaks at $510^{\circ} \mathrm{C}$ and above $700^{\circ} \mathrm{C}$ were observed, respectively. ${ }^{40}$ With $\mathrm{Pd}$ present, the TPR profile dramatically changed. The intensity of the reduction peak at $510{ }^{\circ} \mathrm{C}$ decreased and a new reduction peak appeared at $205{ }^{\circ} \mathrm{C}$ for 0.1 $\mathrm{Pd} / \mathrm{CeO}_{2}$. The reduction peak gradually shifted toward lower temperature with increasing $\mathrm{Pd}$ surface density, appearing at $125^{\circ} \mathrm{C}$ for $0.4 \mathrm{Pd} / \mathrm{CeO}_{2} \cdot{ }^{45-47}$ At even higher surface $\mathrm{Pd}$ density, very sharp and intense reduction peaks arose under $100^{\circ} \mathrm{C}$.

Table 2. Summary of $\mathrm{H}_{2}$-TPR over $\mathrm{Pd} / \mathrm{CeO}_{2}$

\begin{tabular}{|c|c|c|c|c|c|c|}
\hline \multirow[b]{2}{*}{ Catalyst } & \multirow{2}{*}{$\begin{array}{c}\text { Pd } \\
\text { content } \\
\left(\mu \mathrm{mol} P d / g_{c}\right. \\
\text { at })\end{array}$} & \multirow[b]{2}{*}{$\begin{array}{c}\text { Surface Pd } \\
\text { density } \\
\left(\mathbf{P d} / \mathrm{nm}^{2}\right)\end{array}$} & \multicolumn{3}{|c|}{$\mathrm{H}_{2}-\mathrm{TPR}\left(<300^{\circ} \mathrm{C}\right)$} & \multirow[b]{2}{*}{$\begin{array}{c}\text { Specific } \\
\text { activity } \\
\times 10^{2(b)}\end{array}$} \\
\hline & & & $\begin{array}{c}\text { Reduction } \\
\text { temperature } \\
\left({ }^{\circ} \mathrm{C}\right)\end{array}$ & $\begin{array}{c}\mathrm{H}_{2} \text { consumption } \\
\left(\mu \mathrm{mol} / \mathrm{g}_{\text {cat }}\right)\end{array}$ & $\begin{array}{l}\mathrm{CeO}_{2} \text { reduction } \\
\left(\mu \mathrm{mol} / \mathrm{g}_{\text {cat }}\right) \text { (a) }\end{array}$ & \\
\hline $0.1 \mathrm{Pd} / \mathrm{CeO}_{2}$ & 2.4 & 0.1 & 205 & 56.2 & 53.9 & 3.9 \\
\hline $0.2 \mathrm{Pd} / \mathrm{CeO}_{2}$ & 4.7 & 0.2 & 192 & 64.5 & 59.8 & 12.1 \\
\hline $0.4 \mathrm{Pd} / \mathrm{CeO}_{2}$ & 9.4 & 0.4 & 129 & 77.5 & 68.1 & 22.1 \\
\hline $1.2 \mathrm{Pd} / \mathrm{CeO}_{2}$ & 28.3 & 1.2 & 73 & 92.1 & 63.8 & 10.9 \\
\hline $4 \mathrm{Pd} / \mathrm{CeO}_{2}$ & 94.3 & 4.1 & 36 & 125.6 & 31.3 & 6.9 \\
\hline
\end{tabular}

(a) $\mathrm{CeO}_{2}$ reduction $\left(\mu \mathrm{mol} / \mathrm{g}_{\text {cat }}\right)=\mathrm{H}_{2}$ consumption $-\mathrm{Pd}$ content

(b) Specific activity $\left(\mathrm{s}^{-1}\right)$ at steady state

$\mathrm{H}_{2}$-TPR clearly reveals that the hydrogen consumption (see Table 2) far exceeded the amount of $\mathrm{Pd}$ loaded. We calculated the contribution from $\mathrm{CeO}_{2}$ reduction by subtracting off the $\mathrm{H}_{2}$ needed for $\mathrm{Pd}$ reduction. Reduction increased with surface $\mathrm{Pd}$ density at atomic $\mathrm{Pd}$ dispersion (0.1-0.4 Pd/nm²) and follows a linear trend just like the specific activity (Figure S9). This result suggests a causal relationship between enhanced reducibility of $\mathrm{CeO}_{2}$ and increase in specific activity, ultimately derived from higher surface Pd density. As the Pd loading is further increased past $0.4 \mathrm{Pd} / \mathrm{nm}^{2}, \mathrm{CeO}_{2}$ reduction decreased and correspondingly, so did specific activity. This could be due to a decrease in Pd dispersion, but may also be due to lattice oxygen deactivation, which we will return to shortly. As seen in Figure 2(b), the reduction temperature of $\mathrm{Pd} / \mathrm{Al}_{2} \mathrm{O}_{3}$ catalysts was not affected by the surface $\mathrm{Pd}$ density. Very small amounts of $\mathrm{H}_{2}$ were consumed at low-temperature $\left(<50{ }^{\circ} \mathrm{C}\right)$ on $0.017-0.20 \mathrm{Pd} / \mathrm{Al}_{2} \mathrm{O}_{3}$ and a strong reduction peak is observed only with $0.68 \mathrm{Pd} / \mathrm{Al}_{2} \mathrm{O}_{3}$, well beyond the point at which nanoparticles form. ${ }^{48,49}$ 

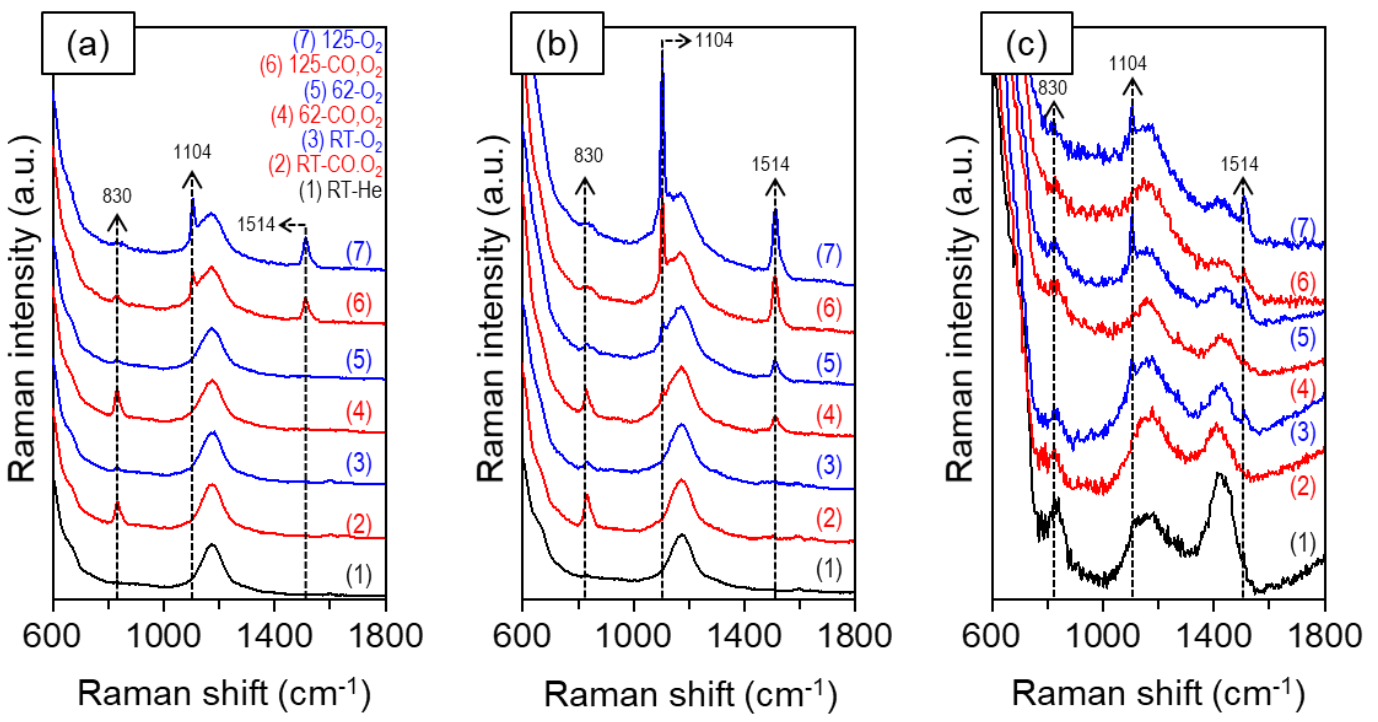

Figure 3. in-situ Raman spectra of (a) $0.2 \mathrm{Pd} / \mathrm{CeO}_{2}$, (b) $0.4 \mathrm{Pd} / \mathrm{CeO}_{2}$ and (c) $4 \mathrm{Pd} / \mathrm{CeO}_{2}$ ((1) room temperature

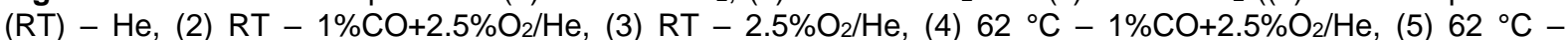
$2.5 \% \mathrm{O}_{2} / \mathrm{He},(6) 125^{\circ} \mathrm{C}-1 \% \mathrm{CO}+2.5 \% \mathrm{O}_{2} / \mathrm{He}$, and $\left.(7) 125^{\circ} \mathrm{C}-2.5 \% \mathrm{O}_{2} / \mathrm{He}\right)$. Raman intensity was normalized with $\mathrm{F}_{2 \mathrm{~g}}\left(450-470 \mathrm{~cm}^{-1}\right)$ band. The same scale of $\mathrm{y}$-axis is used for the figures.

To investigate the observed $\mathrm{CeO}_{2}$ reduction under reaction conditions, we performed in-situ Raman spectroscopy on the $0.2,0.4$ and $4 \mathrm{Pd} / \mathrm{CeO}_{2}$ catalysts at room temperature (RT), $62^{\circ} \mathrm{C}$, and $125^{\circ} \mathrm{C}$. The results obtained are displayed in Figure 3. All samples were pretreated at $350^{\circ} \mathrm{C}$ in $20 \% \mathrm{O}_{2} / \mathrm{He}$ for $0.5 \mathrm{~h}$. At RT under He only, a Raman band representative of $\mathrm{CeO}_{2}$ at $450-470 \mathrm{~cm}^{-1}$ was observed along with weak bands at 270,600 and $1174 \mathrm{~cm}^{-1}$ (Figure S10). ${ }^{40,50,51}$ In $\mathrm{CO}+\mathrm{O}_{2}$, a distinct band at $830 \mathrm{~cm}^{-1}$ was observed for 0.2 and $0.4 \mathrm{Pd} / \mathrm{CeO}_{2}$ catalysts. On the $4 \mathrm{Pd} / \mathrm{CeO}_{2}$ catalyst, this Raman band was rather intense after pre-treatment and $\mathrm{He}$ flushing, but this band decreased in the presence of $\mathrm{CO}+\mathrm{O}_{2}$ at room temperature. The $830 \mathrm{~cm}^{-1}$ band has been attributed to adsorbed peroxide species $\left(\mathrm{O}_{2}{ }^{2-}\right)$ on isolated twoelectron defect sites, indicating oxygen vacancy is formed on $\mathrm{Pd} / \mathrm{CeO}_{2}$ under reaction condition. ${ }^{50}$ As $\mathrm{CO}$ is removed from the gas stream, the characteristic Raman band for the peroxide disappeared on both single atom-containing catalysts $\left(0.2\right.$ and $\left.0.4 \mathrm{Pd} / \mathrm{CeO}_{2}\right)$. At $62{ }^{\circ} \mathrm{C}$, the Raman band of peroxide species re-appeared in the $\mathrm{CO}+\mathrm{O}_{2}$ stream. The most noticeable feature is the development of new bands at 1104 and $1514 \mathrm{~cm}^{-1}$ for the $0.4 \mathrm{Pd} / \mathrm{CeO}_{2}$. These bands are assigned to superoxide $\left(\mathrm{O}_{2}^{-}\right)$and weakly bound dioxygen $\left(\mathrm{O}_{2}{ }^{\delta-}\right)$ species, respectively. ${ }^{52}$ According to Hess et al. ${ }^{52}$ those two dioxygen species can be attributed to the 
creation of oxygen vacancies during $\mathrm{CO}$ oxidation and transfer of electron to adsorbed oxygen molecule. As the temperature was further increased to $125^{\circ} \mathrm{C}$, the peroxide peak $\left(830 \mathrm{~cm}^{-1}\right)$ appeared in a weak intensity under $\mathrm{CO}+\mathrm{O}_{2}$ flow. Features for superoxide $\left(1104 \mathrm{~cm}^{-1}\right)$ and weakly bound dioxygen $\left(1514 \mathrm{~cm}^{-1}\right)$ appeared on $0.2 \mathrm{Pd} / \mathrm{CeO}_{2}$, but their intensities were much lower than in the $0.4 \mathrm{Pd} / \mathrm{CeO}_{2}$ catalyst. When $\mathrm{CO}$ was taken out of the gas stream, the two features became very prominent on both 0.2 and $0.4 \mathrm{Pd} / \mathrm{CeO}_{2}$ catalysts, which might be due to reaction of the charged oxygen species $\left(\mathrm{O}_{2}{ }^{-}\right.$or $\left.\mathrm{O}_{2}{ }^{\delta-}\right)$ with gas phase $\mathrm{CO}$ or removal of adsorbed $\mathrm{CO}$ on oxygen vacancies. On the other hand, as the surface Pd density further increased to 4 , the intensity of the dioxygen species became significantly lower than over 0.4 $\mathrm{Pd} / \mathrm{CeO}_{2}$. The comparison of Raman spectra of 0.2 and $0.4 \mathrm{Pd} / \mathrm{CeO}_{2}$ catalysts clearly shows the facile formation of oxygen vacancies on $\mathrm{CeO}_{2}$ surface with higher surface density of single $\mathrm{Pd}$ atoms in reaction conditions. This result manifests itself in improved oxygen vacancy formation with surface density of atomic $\mathrm{Pd}$, consistent with results from $\mathrm{H}_{2}$-TPR.

In situ transmission FTIR spectroscopy was used to monitor both the nature of Pd species 15 present on the $\mathrm{CeO}_{2}$ support after oxidation at $623 \mathrm{~K}$ and the variation of the reducibility of $\mathrm{CeO}_{2}$ as a function of $\mathrm{Pd}$ loading using $\mathrm{CO}$ as a probe molecule. The IR spectra collected during sequential $\mathrm{CO}$ adsorption over $\mathrm{Pd} / \mathrm{CeO}_{2}$ catalysts with $\mathrm{Pd}$ loadings of $0.2,0.4$ and 4 $\mathrm{Pd} / \mathrm{nm}^{2}$ are displayed in Figure S11. IR bands characteristic of $\mathrm{Pd}$ ions are observed exclusively for the $0.2 \mathrm{Pd} / \mathrm{CeO}_{2}$ sample with characteristic IR features centered between 2098 20 and $2154 \mathrm{~cm}^{-1}$. The $0.4 \mathrm{Pd} / \mathrm{CeO}_{2}$ catalyst exhibits similar IR features of adsorbed $\mathrm{CO}$, however, the intensity ratio of the high and low frequency bands changes dramatically as the Pd loading increases, indicating changes in the population of Pd ions in different environments on(in) the $\mathrm{CeO}_{2}$ surface. The series of IR spectra collected from the $4 \mathrm{Pd} / \mathrm{CeO}_{2}$ sample is fundamentally different from the those of the other two catalysts: they are dominated by IR features of CO 25 adsorbed on metallic Pd sites (Pd particles). IR bands at 2082-2098 and at 1917-1952 $\mathrm{cm}^{-1}$ represent $\mathrm{CO}$ molecules bound linearly and in a bridging configuration to $\mathrm{Pd}^{0}$ centers of metal particles, respectively. It is very interesting to note that upon CO introduction onto all three samples the formation of $\mathrm{CO}_{2}$ is clearly observed. However, while $\mathrm{CO}_{2}$ is present as an 
adsorbed species (sharp IR band at $2351 \mathrm{~cm}^{-1}$ ) on the atomically dispersed $\mathrm{Pd} / \mathrm{CeO}_{2}$ samples, we only observe the formation of gas phase $\mathrm{CO}_{2}\left(2349 \mathrm{~cm}^{-1}\right)$ over the $\mathrm{Pd}$ particles. We propose that the origin of $\mathrm{CO}_{2}$ formed over the single atom-containing samples is fundamentally different from that formed on supported Pd particles. The results of DFT calculations, which will be discussed below, clearly demonstrate that the presence of single $\mathrm{Pd}$ atoms significantly reduces the energy of oxygen vacancy formation on $\mathrm{CeO}_{2}$. This, in turn, means that certain oxygen species on the $\mathrm{CeO}_{2}$ surface in the vicinity of single $\mathrm{Pd}$ atoms become very reactive toward $\mathrm{CO}$, and readily produce $\mathrm{CO}_{2}$. Since these experiments are carried out at room temperature the thus-formed $\mathrm{CO}_{2}$ stays on the $\mathrm{CeO}_{2}$ surface interacting 10 with the oxygen vacancies. In contrast, when $\mathrm{Pd}$ particles are present on the $\mathrm{CeO}_{2}$ support, $\mathrm{CO}_{2}$ is formed by the reaction of $\mathrm{CO}$ with the surface oxide layer formed on the Pd particles during the $673 \mathrm{~K}$ oxidation prior to $\mathrm{CO}$ adsorption. 


\section{Calculated Properties of the $\mathrm{Pd} / \mathrm{CeO}_{2}$ System}

Density functional theory calculations, on the dominant oxygen-terminated $\mathrm{CeO}_{2}(100)$, were employed to provide molecular level insights into the effect of surface Pd density on CO oxidation activity. The 4-fold hollow sites of this surface can stabilize Pd adatoms. However, as shown in Figure S12, upon deposition of single Pd atoms, exposing the stoichiometric $\mathrm{CeO}_{2}(100)$ surface to any partial pressure of oxygen will result in the irreversible adsorption of one additional $\mathrm{O}_{2}$ molecule per $\mathrm{Pd}$ atom to form $\left(\mathrm{PdO}_{2}\right)_{1}$ single-metal-centers, see Figure S12a. These $\left(\mathrm{PdO}_{2}\right)_{1}$ reside in a square planar configuration, with a 4-fold $\mathrm{Pd}$ coordination to surface-bound oxygen atoms, labeled $\mathrm{O} 1-\mathrm{O} 4$ in Figure 4a, $\mathrm{Pd}-\mathrm{O}$ bond lengths of $1.94 \AA$ $1.98 \AA$. This is in excellent agreement with the EXAFS results shown in Table 1 (CN of 3.8 and Pd-O bond length of $1.99 \AA$ ). Increasing the surface Pd density therefore corresponds to decreasing the spatial separation of these $\left[\mathrm{PdO}_{4}\right]$ sites.

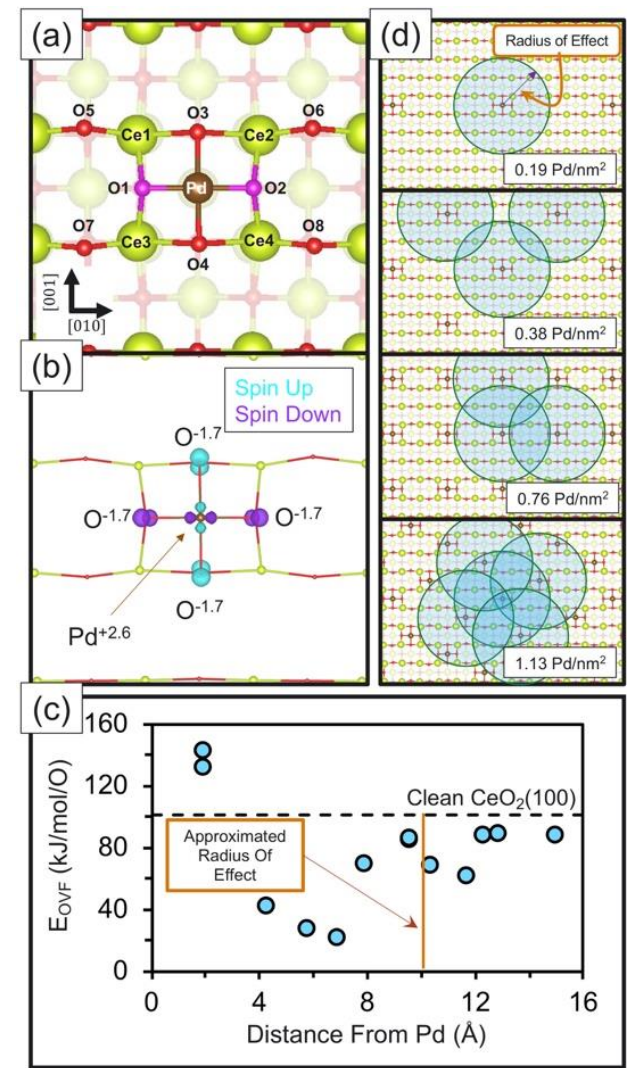

Figure 4. (a) Top-down view of the square planar $\left[\mathrm{PdO}_{4}\right]$ active site on the $\mathrm{CeO}_{2}(100)$ surface with atoms nearby Pd labeled to aid discussion found in the SI. (b) Spin density plot of the [ $\left.\mathrm{PdO}_{4}\right]$ active site. (c) Oxygen vacancy formation energies (Eovf) as a function of distance from Pd. (d) Approximate zone(s) of effect (semi-transparent blue circles) of each [ $\left.\mathrm{PdO}_{4}\right]$, illustrating how overlapping zones produce a cumulative effect as $\mathrm{Pd}$ surface density increases. Brown atoms are $\mathrm{Pd}$, green and red atoms are $\mathrm{Ce}$ and $\mathrm{O}$ of the $\mathrm{CeO}_{2}(100)$ surface, respectively, and the two magenta atoms are $\mathrm{O}$ adatoms. 
Through Bader analysis of the electron and spin density around each atom in and surrounding the $\left[\mathrm{PdO}_{4}\right]$ complex (see the $\mathrm{SI}$ for details), we are able to determine their electronic states. We find that Pd is in an unusually overoxidized 2.6+ state (consistent with our XANES results) with its surrounding $\mathrm{O}$ atoms in markedly unsaturated charge states of 1.7-. The incomplete valence saturation of $\mathrm{Pd} 4 \mathrm{~d}$ and $\mathrm{O} 2 \mathrm{p}$ orbitals can be seen in Figure $4 b$, clearly showing the presence of spin density (i.e., unpaired charge) in these orbitals, indicative of partially charged states. This overoxidation occurs because the two additional $\mathrm{O}$ atoms $(\mathrm{O} 1$ and $\mathrm{O} 2$ in Figure 4a) require four total electrons to reach valence saturation, while neither $\mathrm{Pd}$ nor the $\mathrm{Ce}^{4+}$ of the surface can be oxidized sufficiently to provide all four of these electrons. Instead, Pd provides 2.6 electrons (apparently the limit of its reducing power) and the remaining electron deficiency is shared equally amongst the $4 \mathrm{Pd}$-coordinated $\mathrm{O}$ atoms $(\mathrm{O} 1$ O4 in Figure 4a) via charge delocalization.

This overall 2e- deficiency of the $\mathrm{PdO}_{4}$ moiety suggests that it would be an excellent oxidizer whenever the nearby $\mathrm{CeO}_{2}$ surface is reduced as in $\mathrm{CO}$ oxidation via the MvK mechanism. We confirm this by calculating the oxygen vacancy formation energy (OVFE) of $O$ atoms as a function of their distance from Pd. The results, shown in Figure 4c, are compared against the calculated OFVE of the pristine $\mathrm{CeO}_{2}(100)$ surface $(\sim 102 \mathrm{~kJ} / \mathrm{mol} / \mathrm{O})$. Intriguingly, while the $\mathrm{O}$ atoms in $\left[\mathrm{PdO}_{4}\right]$ are more difficult to remove (OVFEs of $\sim 133$ and $\sim 143 \mathrm{~kJ} / \mathrm{mol} / \mathrm{O}$ ) than those of the pristine surface, nearby $\mathrm{O}$ atoms are made dramatically more reactive (OVFEs of $22-$ $2043 \mathrm{~kJ} / \mathrm{mol}$ ). The effect is diminished around a Pd-O distance of $\sim 8 \AA$ (OVFE of $70 \mathrm{~kJ} / \mathrm{mol}$ ) reaching a plateau (of $\sim 88 \mathrm{~kJ} / \mathrm{mol}$ ) at $\sim 12 \AA$. As a difference in reducibility between 0.1 and $0.2 \mathrm{Pd} / \mathrm{nm}^{2}$ is seen in our $\mathrm{H}_{2}$-TPR experiments, and our model only allows for a minimum surface density of $\sim 0.19 \mathrm{Pd} / \mathrm{nm}^{2}$, we suspect a significantly larger distance is required to completely recover pristine surface behavior. Using the average of $8 \AA$ and $12 \AA$ as an 25 approximate "radius of $\left[\mathrm{PdO}_{4}\right]$ effect", we overlay an illustrative "zone of influence" (semitransparent blue circles in Figure $4 \mathrm{~d}$ ) around each $\left[\mathrm{PdO}_{4}\right]$ at different surface $\mathrm{Pd}$ densities wherein $\mathrm{O}$ atoms are likely activated. Interestingly, areas begin to overlap as surface $\mathrm{Pd}$ 
density increases, encompassing neighboring $\left[\mathrm{PdO}_{4}\right]$ by $1.13 \mathrm{Pd} / \mathrm{nm}^{2}$. This suggests a cumulative effect on oxygen activity as surface Pd density increases.
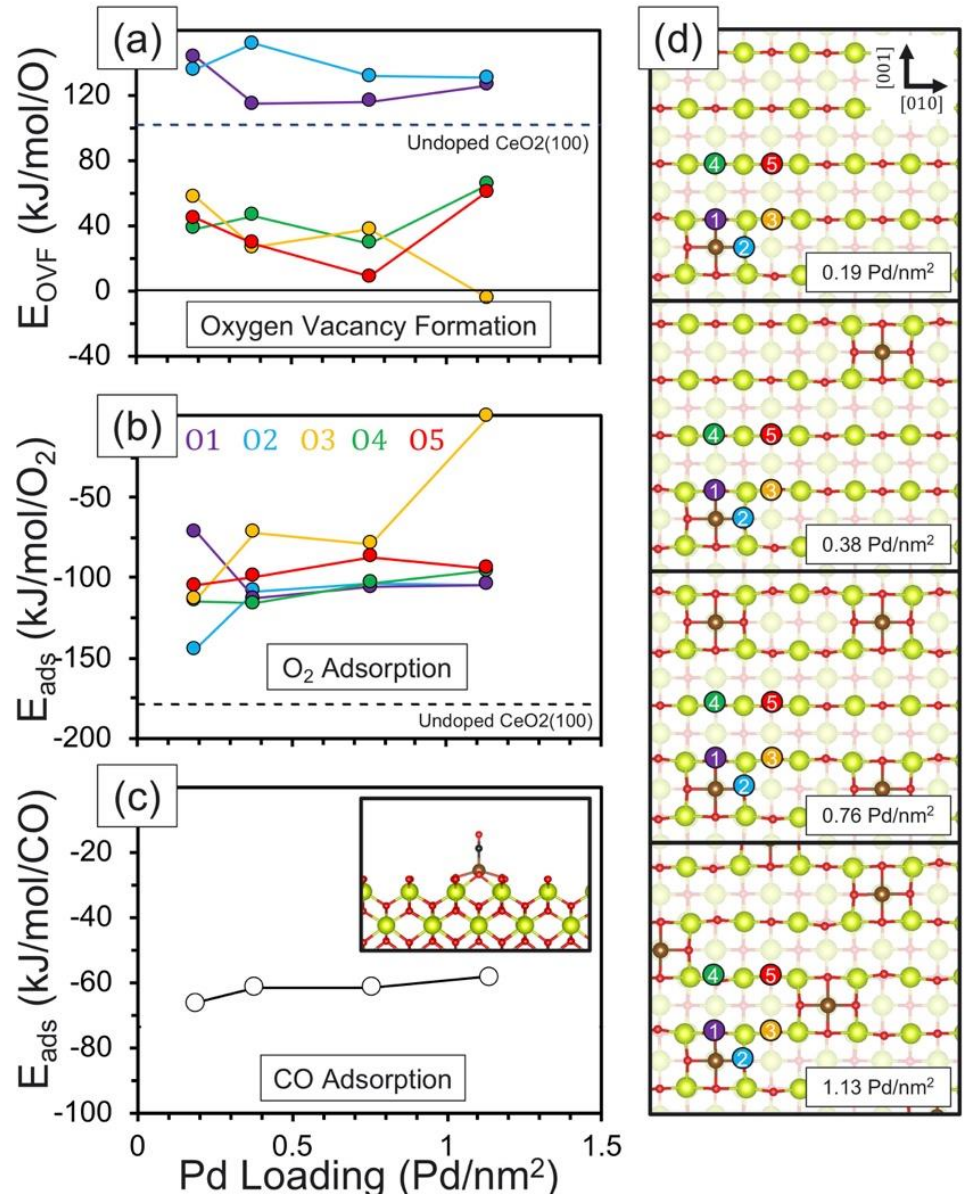

Figure 5. Quantities computed as a function of Pd Loading: (a) oxygen vacancy formation energies, (b) oxygen adsorption energies, and (c) average $\mathrm{CO}$ adsorption energies (side view of the corresponding ball-and-stick model is shown inset). (d) Ball-and-stick models of the four surface Pd densities computed here. Symmetrically distinct $O$ atoms are labeled $1-5$ in each panel of (d). Each series in (a) and (b) corresponds to removal of the labeled $\mathrm{O}$ atoms or adsorption of an additional $\mathrm{O}$ atom to the labeled $\mathrm{O}$ atoms to form a superoxo $\left(\mathrm{O}_{2}-\right)$. The series in (c) corresponds to the adsorption of $\mathrm{CO}$ on all single $\mathrm{Pd}$ atom centers available in each system in (d).

To test this presumption, we compute OVFEs for the five most proximal (out to $\sim 8 \AA$ ) 0 atoms to $\mathrm{Pd}$ (including the $\mathrm{O}$ atoms in $\left[\mathrm{PdO}_{4}\right]$ ) as a function of surface $\mathrm{Pd}$ density, shown in Figure 5a. The results indicate that oxygen activity is progressively enhanced as surface $\mathrm{Pd}$ density increases, with a general downward trend in OVFEs seen for the $\mathrm{O}$ atoms not directly coordinated to $\mathrm{Pd}$ (labeled $\mathrm{O} 3$ - $\mathrm{O} 5$ in Figure 4). Regardless of surface Pd density, the Pdcoordinated $\mathrm{O}$ atoms (labeled $\mathrm{O} 1$ and $\mathrm{O} 2$ in Figure 4) remain more tightly bound than $\mathrm{O}$ atoms in pristine $\mathrm{CeO}_{2}(100)$, indicating these $\mathrm{O}$ atoms are not likely involved in the $\mathrm{CO}$ oxidation reaction. In Figure 5b and 5c, respectively, we show that $\mathrm{O}_{2}$ and $\mathrm{CO}$ adsorption energies are 
minimally affected by surface Pd density, indicating that the primary cause of the enhanced $\mathrm{CO}$ oxidation activity, as seen in experiment, is driven by the increased $\mathrm{O}$ reactivity. An analysis of the charge distribution, seen in Figures $\mathrm{S} 16-\mathrm{S} 18$, reveals that $\left[\mathrm{PdO}_{4}\right]$ is consistently reduced after $\mathrm{O}$ atom removal, regardless of which $\mathrm{O}$ atom is removed. As can be seen in Figure $\mathrm{S} 19$, for the $\mathrm{O} 3$ atom most proximal to $\left[\mathrm{PdO}_{4}\right]$, the most likely participant in CO oxidation, the OVFEs correlate well with the change in work function $(\Delta \Phi)$, with large $\Delta \Phi$ corresponding to the highest OVFEs. This indicates that nonlocal electrostatic effects to be the source of the observed OVFE trends.

The OVFE and $\mathrm{O}_{2}$ adsorption energy of $\mathrm{O} 3$ at surface $\mathrm{Pd}$ density of $1.13 \mathrm{Pd} / \mathrm{nm}^{2}$ (see Figure $5 a$ and $5 b)$ deserves highlighting. We find that the OVFE is thermoneutral to within expected errors, suggesting that this $\mathrm{O}$ atom should be very active. However, the subsequent readsorption of $\mathrm{O}_{2}$ is lacking an enthalpic driving force so once this $\mathrm{O}$ vacancy forms, it will be permanent. This is consistent with experimental results that showed decreased oxygen species adsorption on oxygen vacancies on $4 \mathrm{Pd} / \mathrm{CeO}_{2}$ (Figure 3). As can be seen in Figure S20, up to 4 such proximal $\mathrm{O}$ atoms can be removed, corresponding to two thirds of the available $\left[\mathrm{PdO}_{4}\right]$ active sites. This is a significant loss of active $\mathrm{O}$ atoms and may explain the experimentally observed loss in specific activity (Figure 1) beyond simple Pd agglomeration.

\section{CONCLUSIONS}

Our study highlights a synergy between single $\mathrm{Pd}$ atoms on $\mathrm{CeO}_{2}$ and enhanced catalytic activity, in contrast to the constant-activity behavior typically assumed for single atom catalysts. By combining activity measurements, $\mathrm{H}_{2}$-TPR, Raman spectroscopy, FTIR, and DFT calculations, we demonstrate that this improvement is due to increased activity of $\mathrm{O}$ atoms proximal to $\mathrm{Pd}$, with a surprisingly large area of influence (at minimum $2.0 \mathrm{~nm}^{2}$ ) and $\mathrm{O}$ activity accumulation as surface $\mathrm{Pd}$ density increases. This unique behavior, characteristic of $\mathrm{CeO}_{2}$ but absent in $\mathrm{Al}_{2} \mathrm{O}_{3}$, emphasizes the importance of the support. 
XANES, EXAFS, DFT and charge analysis allowed us to characterize the $\mathrm{Pd} / \mathrm{CeO}_{2}$ active site as an overoxidized square planar $\left[\mathrm{PdO}_{4}\right]$ complex with $\mathrm{Pd}$ in an approximate +2.6 oxidation state and unsaturated valence $O$ atoms in approximately -1.7 oxidation states. The oxidative power of $\left[\mathrm{PdO}_{4}\right]$ is also shown to have a large lateral range of effect on oxygen activity that accumulates as surface density of $\left[\mathrm{PdO}_{4}\right]$ increases. This stems from the ability of $\mathrm{CeO}_{2}$ to shuttle charge from oxygen vacancies to the $\left[\mathrm{PdO}_{4}\right]$ complex, which reduces it to a more stable oxidation state. Both Raman spectroscopy and DFT calculations reveal the limits of this cumulative effect at high surface Pd densities result in overactivation and permanent removal of previously active $\mathrm{O}$ atoms. Overall, the most interesting feature is direct correlation

10 of specific activity to $\mathrm{CeO}_{2}$ reducibility rather than $\mathrm{Pd}$. This work invites further investigation into the origin and manifestation of nonlocal effects in single atom catalysts that have hitherto received little attention. 


\section{METHODS}

Catalysts preparation

The nanocube $\mathrm{CeO}_{2}$ support, dominated by (100) facets, was hydrothermally synthesized in Teflon-lined stainless steel autoclaves as previous report. ${ }^{40} \mathrm{Pd} / \mathrm{CeO}_{2}$ catalysts were prepared by incipient wetness impregnation using $\mathrm{Pd}\left(\mathrm{NH}_{3}\right)_{4}\left(\mathrm{NO}_{3}\right)_{2}$ solution followed by calcination at $400{ }^{\circ} \mathrm{C}$ for $4 \mathrm{~h}$ under air. $\mathrm{Pd} / \mathrm{Al}_{2} \mathrm{O}_{3}$ catalysts were prepared by same method using commercial $\mathrm{y}-\mathrm{Al}_{2} \mathrm{O}_{3}$ (PURALOX® SBa200, Sasol, $\mathrm{SA}=200 \mathrm{~m}^{2} / \mathrm{g}$ ). The $\mathrm{Pd} / \mathrm{Al}_{2} \mathrm{O}_{3}$ catalysts were calcined at $700{ }^{\circ} \mathrm{C}$ for $1 \mathrm{~h}$ using $20 \% \mathrm{O}_{2} / \mathrm{He}\left(60 \mathrm{ml} \mathrm{min}^{-1}\right)$ as previous report. ${ }^{23,53}$ Resulting catalysts were designated as as $\boldsymbol{X} \mathrm{Pd} / \mathrm{CeO}_{2}$ and $\boldsymbol{X} \mathrm{Pd} / \mathrm{Al}_{2} \mathrm{O}_{3}\left(\boldsymbol{X}=\right.$ surface $\mathrm{Pd}$ density, $\left.\mathrm{Pd} / \mathrm{nm}^{2}\right)$

10

\section{Catalyst characterization}

1. $\mathrm{CeO}_{2}$ support

XRD pattern of the synthesized $\mathrm{CeO}_{2}$ was obtained on a D8 Advance (Bruker) using $\mathrm{Cu} \mathrm{Ka}$ radiation $(\lambda=1.5406 \AA)$ at $40 \mathrm{kV}$ and $40 \mathrm{~mA}$, with a step size of 0.05 in $2 \theta$ and a time per step 15 of $0.5 \mathrm{sec}$ in the $2 \theta$ range from 10 to $110^{\circ}$. BET surface area was determined via $\mathrm{N}_{2}$ adsorption with a BELSORP-max system (Bel Japan) after degas at $150^{\circ} \mathrm{C}$ for $4 \mathrm{~h}$. Scanning electron microscopy (SEM) was performed using an SU-8220 (Hitachi). Transmission electron microscopy (TEM) was performed using a JEM-2100 (JEOL).

2. $\mathrm{Pd} / \mathrm{CeO}_{2}$ and $\mathrm{Pd} / \mathrm{Al}_{2} \mathrm{O}_{3}$ catalysts

20 AC-HAADF-STEM was performed using JEM-2100F (JEOL). XAFS at Pd K-edge (24350 $\mathrm{eV}$ ) were performed in fluorescence mode at the 7D beamline of the Pohang Accelerator Laboratory (PLS-II). The data was analyzed by the standard method using the Ab-initio Feff program. ${ }^{54}$

$\mathrm{H}_{2}$-TPR experiments were carried out using BELCAT-II (Bel Japan). $0.05 \mathrm{~g}$ of $\mathrm{Pd} / \mathrm{CeO}_{2}$ catalysts were pretreated at $400{ }^{\circ} \mathrm{C}$ for $30 \mathrm{~min}$ under $20 \% \mathrm{O}_{2} / \mathrm{He}$ flow $\left(60 \mathrm{ml} \mathrm{min}^{-1}\right) .0 .1 \mathrm{~g}$ of $\mathrm{Pd} / \mathrm{Al}_{2} \mathrm{O}_{3}$ catalysts were pretreated at $700{ }^{\circ} \mathrm{C}$ for $30 \mathrm{~min}$ under $20 \% \mathrm{O}_{2} / \mathrm{He}$ flow $\left(60 \mathrm{ml} \mathrm{min}{ }^{-1}\right)$. After calcination, the samples were cooled to $-80^{\circ} \mathrm{C}$. The thermal conductivity detector (TCD) 
signal was stabilized for $2 \mathrm{~h}$ and reduction was carried out under a flow of $2 \% \mathrm{H}_{2} / \mathrm{Ar}(60 \mathrm{ml}$ $\min ^{-1}$ ) at a ramp rate of $10^{\circ} \mathrm{C} \mathrm{min}-1$. The amount of $\mathrm{H}_{2}$ consumed was determined from the TCD signal intensities calibrated using pulse of known amount of $\mathrm{H}_{2} .13 \mathrm{X}$ molecular sieve was used to remove water produced during the catalyst reduction.

In-situ Raman analysis was performed on WITec alpha300R Micro-imaging Raman Spectrometer equipped with a 532-nm (3.0 mW) Nd-YAG excitation laser and 40x Nikon objective (NA = 0.6). A spectrometer with a grating of $600 \mathrm{gr} / \mathrm{nm}$ was used. The $\mathrm{Pd} / \mathrm{CeO}_{2}$ catalysts was loaded into a high-temperature reaction chamber (Harrick scientific) and pretreated at $350{ }^{\circ} \mathrm{C}$ for $0.5 \mathrm{~h}$ under $\left.20 \% \mathrm{O}_{2} / \mathrm{He}(60 \mathrm{ml} \mathrm{min})^{-1}\right)$. The catalysts were cooled to room temperature $(\mathrm{RT})$ and purged with $\mathrm{He}\left(60 \mathrm{ml} \mathrm{min}^{-1}\right)$ for $30 \mathrm{~min}$. The catalysts were exposed to $1 \% \mathrm{CO}+2.5 \% \mathrm{O}_{2} / \mathrm{He}$ and $2.5 \% \mathrm{O}_{2} / \mathrm{He}\left(60 \mathrm{ml} \mathrm{min} \mathrm{m}^{-1}\right)$ for $5 \mathrm{~min}$ in each condition at selected temperatures (RT, 62 and $\left.125^{\circ} \mathrm{C}\right)$. The spectral acquisition was executed with 20 scans at 3 s/scan using an electrically cooled CCD detector.

In situ transmission FTIR experiments were carried out on selected $\mathrm{Pd} / \mathrm{CeO}_{2}$ samples using 15 CO as a probe molecule. The home-built IR cell consists of $2 \frac{3 / 4}{4}$ stainless steel cube equipped with $\mathrm{CaF}_{2}$ windows, connected to a gas handling manifold and a pumping station. The powder samples were pressed onto a tungsten mesh (>80\% IR transmission) and mounted onto a copper sample holder assembly attached to the $\mathrm{Cu}$ heating legs of a ceramic feed through. The sample can be heated resistively, and its temperature is monitored by a $\mathrm{K}$ type 20 thermocouple spotwelded to the top center of the W mesh. IR spectra were collected with Bruker Vertex 70 spectrometer equipped with a liquid nitrogen-cooled MCT detector. All the spectra were collected at $4 \mathrm{~cm}^{-1}$ resolution and each spectrum was the average of 256 scans. The samples were first oxidized at $673 \mathrm{~K}$ in $\sim 1$ Torr of $\mathrm{O}_{2}$ for $1 \mathrm{~h}$, cooled to $295 \mathrm{~K}$ in $\mathrm{O}_{2}$ before evacuating the cell. After evacuation ( $<5 \times 10^{-8}$ Torr) a background spectrum was collected with 25 the sample in the IR beam followed by sequential $\mathrm{CO}$ introduction into the cell. After equilibration following each $\mathrm{CO}$ aliquot an IR spectrum was collected. The highest equilibrium CO pressure in the IR cell $\sim 0.4$ Torr. 


\section{Catalyst performance}

$\mathrm{CO}$ oxidation reaction tests were performed in a quartz flow reactor using $0.02 \mathrm{~g}$ catalysts supported by quartz wool. Prior to reaction test, $\mathrm{Pd} / \mathrm{CeO}_{2}$ and $\mathrm{Pd} / \mathrm{Al}_{2} \mathrm{O}_{3}$ catalysts were pretreated under a flow of $20 \% \mathrm{O}_{2} / \mathrm{He}$ (total flow rate of $60 \mathrm{ml} \mathrm{min}^{-1}$ ) for $30 \mathrm{~min}$ at $400{ }^{\circ} \mathrm{C}$ and for $1 \mathrm{~h}$ at $700{ }^{\circ} \mathrm{C}$, respectively. The activity was measured at $75^{\circ} \mathrm{C}$ with feed gas of $1 \% \mathrm{CO}$ and $2.5 \% \mathrm{O}_{2}$ in $\mathrm{He}$ (total flow rate of $60 \mathrm{ml} \mathrm{min}^{-1}$ ). The outlet gases were analyzed by Agilent 7820A gas chromatograph (GC) using HP-PLOT Q column and TCD. For reasonable conversion level $\left(<10 \%\right.$ ), the catalysts were diluted with an $\mathrm{Al}_{2} \mathrm{O}_{3}$ (for $\mathrm{Pd} / \mathrm{CeO}_{2}$ catalysts) or quartz (for $\mathrm{Pd} / \mathrm{Al}_{2} \mathrm{O}_{3}$ catalysts) if needed $\left(\mathrm{m}_{\text {cat }+ \text { diluent }}=0.02 \mathrm{~g}\right)$. Specific activity $\left(\mathrm{TOF}, \mathrm{s}^{-1}\right)$ was calculated based on the total Pd loading, assuming 100\% dispersion. Conversions from 110 to 120 minutes were averaged to calculate specific activity at steady state. For $0.1,0.2$ and $0.4 \mathrm{Pd} / \mathrm{CeO}_{2}$ catalysts, the specific activity at steady state was obtained at least 5 different temperatures for linear Arrhenius plots.

\section{DFT calculations}

All calculated solutions to the unrestricted (spin polarized) Kohn-Sham equations on all $\mathrm{Pd} / \mathrm{CeO}_{2}(100)$ systems were performed using the $\mathrm{CP} 2 \mathrm{~K}$ quantum chemical and molecular dynamics simulation package (version 6.1). ${ }^{55}$ The Perdew-Burke-Ernzerhof $(\mathrm{PBE})^{56,57}$ functional was chosen to describe exchange and correlation, while Grimme's D3-type 20 parameterization ${ }^{58}$ with a $15 \AA$ cutoff was chosen to provide dispersion corrections. In CP2K, core electrons and nuclei are described using norm-conserving pseudopotentials of the Goedecker-Tetter-Hutter (GTH) type. ${ }^{59}$ Valence electrons were described in a Gaussian plane wave hybrid basis set scheme ${ }^{60}$, using double- $\zeta$ Gaussian MOLOPT basis sets ${ }^{61}$ (for all elements except $\mathrm{Ce}$ ) along with a plane wave cutoff of $500 \mathrm{Ry}$. To properly capture the electronics and redox properties of $\mathrm{Ce}$, its recently reported LnPP1 GTH basis set and pseudopotential62 were adopted. The $G G A+U$ scheme ${ }^{63}$ was also utilized with an effective 
Hubbard parameter $(\mathrm{U}-\mathrm{J})$ of 0.15 Hartrees $(\sim 4.08 \mathrm{eV})$ selected as specified by Lu et al., ${ }^{62}$ corresponding to LnPP1. Further computational details can be found in the SI.

\section{Data availability}

5 The data that support the findings of this study are available from the corresponding author on request.

\section{Acknowledgements}

We acknowledge the financial support from the National Research Foundation (NRF) (No. 2016R1A5A1009405, 2017R1A2B4007310). Work at the Pacific Northwest National Laboratory (PNNL) was supported by the U.S. Department of Energy, Office of Science, Basic Energy Sciences, Chemical Sciences, Geosciences, and Biosciences Division. PNNL is a multiprogram national laboratory operated for DOE by Battelle under Contract DE-AC0576RL01830. Computational Resources were provided by a user proposal at the National

15 Energy Research Scientific Computing Center (NERSC) located at Lawrence Berkley National Laboratory (LBNL).

\section{Author contributions}

J.H.K. conceived and designed the project. Y.K. carried out the catalyst preparation,

20 characterization and reaction tests. S.J.C performed EXAFS and the data analysis. K.K. and J.S. carried out IR. G.C., M.S.L, V-A.G. and R.R. designed and performed the DFT calculations. All the authors contributed critically for understanding the reaction mechanisms and participated in discussions and writing of the paper.

\section{$25 \quad$ Additional Information}

\section{Competing interests}

The authors declare no competing interests. 


\section{References}

1 Yang, X.-F. et al. Single-Atom Catalysts: A New Frontier in Heterogeneous Catalysis. Acc. Chem. Res. 46, 1740-1748 (2013).

2 Mitchell, S., Vorobyeva, E. \& Pérez-Ramírez, J. The Multifaceted Reactivity of Single-Atom Heterogeneous Catalysts. Angew. Chem. Int. Ed. 57, 15316-15329 (2018).

3 Li, X., Yang, X., Huang, Y., Zhang, T. \& Liu, B. Supported Noble-Metal Single Atoms for Heterogeneous Catalysis. Advan. Mater. 31, 1902031 (2019).

4 Cui, X., Li, W., Ryabchuk, P., Junge, K. \& Beller, M. Bridging homogeneous and heterogeneous catalysis by heterogeneous single-metal-site catalysts. Nat. Catal. 1, 385-397 (2018).

Wang, J., Li, Z., Wu, Y. \& Li, Y. Fabrication of Single-Atom Catalysts with Precise Structure and High Metal Loading. Advan. Mater. 30, 1801649 (2018).

6 Wu, J., Xiong, L., Zhao, B., Liu, M. \& Huang, L. Densely Populated Single Atom Catalysts. Small Methods 4, 1900540 (2020).

7 Tang, C. et al. Coordination Tunes Selectivity: Two-Electron Oxygen Reduction on HighLoading Molybdenum Single-Atom Catalysts. Angew. Chem. Int. Ed. 59, 9171-9176 (2020).

8 Liu, J.-C., Xiao, H. \& Li, J. Constructing High-Loading Single-Atom/Cluster Catalysts via an Electrochemical Potential Window Strategy. J. Am. Chem. Soc. 142, 3375-3383 (2020).

$9 \mathrm{Li}, \mathrm{J}$. et al. Ultrahigh-Loading Zinc Single-Atom Catalyst for Highly Efficient Oxygen Reduction in Both Acidic and Alkaline Media. Angew. Chem. Int. Ed. 58, 7035-7039 (2019).

Zhao, L. et al. Cascade anchoring strategy for general mass production of high-loading singleatomic metal-nitrogen catalysts. Nat. Commun. 10, 1278 (2019).

11 Kunwar, D. et al. Stabilizing High Metal Loadings of Thermally Stable Platinum Single Atoms on an Industrial Catalyst Support. ACS Catal. 9, 3978-3990 (2019).

12 Qiao, B. et al. Ultrastable single-atom gold catalysts with strong covalent metal-support interaction (CMSI). Nano Res. 8, 2913-2924 (2015).

Yang, M. et al. Catalytically active $\mathrm{Au}-\mathrm{O}(\mathrm{OH})_{x}$-species stabilized by alkali ions on zeolites and mesoporous oxides. Science 346, 1498-1501 (2014).

14 Qiao, B. et al. Single-atom catalysis of $\mathrm{CO}$ oxidation using $\mathrm{Pt}_{1} / \mathrm{FeO}_{x}$. Nat. Chem. 3, 634-641 (2011).

Yang, T. et al. A Theoretical Investigation on $\mathrm{CO}$ Oxidation by Single-Atom Catalysts $\mathrm{M}_{1} / \mathrm{Y}-\mathrm{Al}_{2} \mathrm{O}_{3}$ (M=Pd, Fe, Co, and Ni). ChemCatChem 9, 1222-1229 (2017).

16 Wang, Y.-G. et al. $\mathrm{CO}$ Oxidation on $\mathrm{Au} / \mathrm{TiO}_{2}$ : Condition-Dependent Active Sites and Mechanistic Pathways. J. Am. Chem. Soc. 138, 10467-10476 (2016).

17 Yuk, S. F. et al. Selective acetylene hydrogenation over single metal atoms supported on Fe3O4(001): A first-principle study. J. Chem. Phys. 152, 154703 (2020).

18 Lou, Y. \& Liu, J. CO Oxidation on Metal Oxide Supported Single Pt atoms: The Role of the Support. Ind. Eng. Chem. Res. 56, 6916-6925 (2017).

19 Mei, D. et al. Unique Role of Anchoring Penta-Coordinated $\mathrm{Al}^{3+}$ Sites in the Sintering of $\mathrm{Y}^{-} \mathrm{Al}_{2} \mathrm{O}_{3-}$ Supported Pt Catalysts. J. Phys. Chem. Lett. 1, 2688-2691 (2010).

Sarma, B. B. et al. Metal-Specific Reactivity in Single-Atom Catalysts: CO Oxidation on 4d and 5d Transition Metals Atomically Dispersed on MgO. J. Am. Chem. Soc. 142, 14890-14902 (2020).

21 Abbet, S., Heiz, U., Häkkinen, H. \& Landman, U. CO Oxidation on a Single Pd Atom Supported on Magnesia. Phys. Rev. Lett. 86, 5950-5953 (2001).

4522 Zhang, Z. et al. Thermally stable single atom $\mathrm{Pt} / \mathrm{m}-\mathrm{Al}_{2} \mathrm{O}_{3}$ for selective hydrogenation and $\mathrm{CO}$ oxidation. Nat. Commun. 8, 16100 (2017).

23 Peterson, E. J. et al. Low-temperature carbon monoxide oxidation catalysed by regenerable atomically dispersed palladium on alumina. Nat. Commun 5, 4885 (2014).

24 Venkataswamy, P., Jampaiah, D., Lin, F., Alxneit, I. \& Reddy, B. M. Structural properties of alumina supported $\mathrm{Ce}-\mathrm{Mn}$ solid solutions and their markedly enhanced catalytic activity for $\mathrm{CO}$ oxidation. Appl. Surf. Sci. 349, 299-309 (2015).

25 Qiao, B. et al. Highly active $\mathrm{Au}_{1} / \mathrm{Co}_{3} \mathrm{O}_{4}$ single-atom catalyst for $\mathrm{CO}$ oxidation at room 
temperature. Chinese J. Catal. 36, 1505-1511 (2015).

$26 \mathrm{Nie}$, L. et al. Activation of surface lattice oxygen in single-atom $\mathrm{Pt} / \mathrm{CeO}_{2}$ for low-temperature $\mathrm{CO}$ oxidation. Science 358, 1419-1423 (2017).

27 Zhang, X. et al. A Ti-anchored $\mathrm{Ti}_{2} \mathrm{CO}_{2}$ monolayer (MXene) as a single-atom catalyst for $\mathrm{CO}$ oxidation. J. Mater. Chem. A 4, 4871-4876 (2016).

Therrien, A. J. et al. An atomic-scale view of single-site Pt catalysis for low-temperature CO oxidation. Nat. Catal. 1, 192-198 (2018).

Spezzati, G. et al. Atomically Dispersed Pd-O Species on $\mathrm{CeO}_{2}(111)$ as Highly Active Sites for Low-Temperature CO Oxidation. ACS Catal. 7, 6887-6891 (2017).

Spezzati, G. et al. $\mathrm{CO}$ oxidation by Pd supported on $\mathrm{CeO}_{2}(100)$ and $\mathrm{CeO}_{2}(111)$ facets. Appl. Catal. B 243, 36-46 (2018).

Boronin, A. et al. Investigation of palladium interaction with cerium oxide and its state in catalysts for low-temperature CO oxidation. Catal. today 144, 201-211 (2009).

Dessal, C. et al. Dynamics of Single Pt Atoms on Alumina during CO Oxidation Monitored by Operando X-ray and Infrared Spectroscopies. ACS Catal. 9, 5752-5759 (2019).

Cargnello, M. et al. Control of Metal Nanocrystal Size Reveals Metal-Support Interface Role for Ceria Catalysts. Science 341, 771-773 (2013).

Jeong, H., Bae, J., Han, J. W. \& Lee, H. Promoting Effects of Hydrothermal Treatment on the Activity and Durability of $\mathrm{Pd} / \mathrm{CeO} 2$ Catalysts for CO Oxidation. ACS Catal. 7, 7097-7105 (2017). $\mathrm{Hu}, \mathrm{Z}$. et al. Effect of Ceria Crystal Plane on the Physicochemical and Catalytic Properties of $\mathrm{Pd} /$ Ceria for CO and Propane Oxidation. ACS Catal. 6, 2265-2279 (2016).

Jeong, $\mathrm{H}$. et al. Highly durable metal ensemble catalysts with full dispersion for automotive applications beyond single-atom catalysts. Nat. Catal. 3, 368-375 (2020).

$\mathrm{Liu}, \mathrm{X}$. et al. Low-temperature catalytic oxidation of $\mathrm{CO}$ over highly active mesoporous

$\mathrm{Pd} / \mathrm{CeO}_{2}-\mathrm{ZrO}_{2}-\mathrm{Al}_{2} \mathrm{O}_{3}$ catalyst. RSC Adv. 6, 41181-41188 (2016).

38 Slavinskaya, E. M. et al. Metal-support interaction in $\mathrm{Pd} / \mathrm{CeO}_{2}$ model catalysts for $\mathrm{CO}$ oxidation: from pulsed laser-ablated nanoparticles to highly active state of the catalyst. Catal. Sci. Technol. 6, 6650-6666 (2016).

39 Lee, A. F., Hackett, S. F. J., Hargreaves, J. S. J. \& Wilson, K. On the active site in heterogeneous palladium selox catalysts. Green Chem. 8, 549-555 (2006).

$40 \mathrm{Wu}, \mathrm{Z}$., $\mathrm{Li}, \mathrm{M}$. \& Overbury, S. H. On the structure dependence of $\mathrm{CO}$ oxidation over $\mathrm{CeO}_{2}$ nanocrystals with well-defined surface planes. J. Catal. 285, 61-73 (2012).

41 Liu, J.-X., Su, Y., Filot, I. A. W. \& Hensen, E. J. M. A Linear Scaling Relation for CO Oxidation on $\mathrm{CeO}_{2}$-Supported Pd. J. Am. Chem. Soc. 140, 4580-4587 (2018). Ha, H., Yoon, S., An, K. \& Kim, H. Y. Catalytic CO Oxidation over Au Nanoparticles Supported on $\mathrm{CeO}_{2}$ Nanocrystals: Effect of the $\mathrm{Au}-\mathrm{CeO}_{2}$ Interface. ACS Catal. 8, 11491-11501 (2018).

$\mathrm{Liu}, \mathrm{B}$. et al. Interfacial effects of $\mathrm{CeO}_{2}$-supported $\mathrm{Pd}$ nanorod in catalytic $\mathrm{CO}$ oxidation: a theoretical study. J. Phys. Chem. C 119, 12923-12934 (2015).

4 Lohrenscheit, M. \& Hess, C. Direct Evidence for the Participation of Oxygen Vacancies in the Oxidation of Carbon Monoxide over Ceria-Supported Gold Catalysts by using Operando Raman Spectroscopy. ChemCatChem 8, 523-526 (2016).

Kopelent, R. et al. Catalytically Active and Spectator $\mathrm{Ce}^{3+}$ in Ceria-Supported Metal Catalysts. Angew. Chem. Int. Ed. 54, 8728-8731 (2015).

46 Sun, $\mathrm{X}$. et al. $\mathrm{FeO}_{\mathrm{x}}$ supported single-atom $\mathrm{Pd}$ bifunctional catalyst for water gas shift reaction. AIChE J 63, 4022-4031 (2017).

47 Luo, M.-F., Hou, Z.-Y., Yuan, X.-X. \& Zheng, X.-M. Characterization study of $\mathrm{CeO}_{2}$ supported Pd catalyst for low-temperature carbon monoxide oxidation. Catal. Lett. 50, 205-209 (1998). Pd/Ce, 3 , (2014).

49 Vedyagin, A. A. et al. Characterization of active sites of $\mathrm{Pd} / \mathrm{Al}_{2} \mathrm{O}_{3}$ model catalysts with low $\mathrm{Pd}$ content by luminescence, EPR and ethane hydrogenolysis. Appl. Catal. B 103, 397-403 (2011). 
50 Wu, Z., Li, M., Howe, J., Meyer, H. M. \& Overbury, S. H. Probing Defect Sites on $\mathrm{CeO}_{2}$ Nanocrystals with Well-Defined Surface Planes by Raman Spectroscopy and $\mathrm{O}_{2}$ Adsorption. Langmuir 26, 16595-16606 (2010).

51 Filtschew, A., Hofmann, K. \& Hess, C. Ceria and Its Defect Structure: New Insights from a Combined Spectroscopic Approach. J. Phys. Chem. C 120, 6694-6703 (2016).

52 Schilling, C., Ganduglia-Pirovano, M. V. \& Hess, C. Experimental and Theoretical Study on the Nature of Adsorbed Oxygen Species on Shaped Ceria Nanoparticles. J. Phys. Chem. Lett. 9, 6593-6598 (2018).

53 Narula, C. K., Allard, L. F., Moses-DeBusk, M., Stocks, G. M. \& Wu, Z. Single Pd Atoms on $\theta-$ $\mathrm{Al}_{2} \mathrm{O}_{3}$ (010) Surface do not Catalyze NO Oxidation. Sci. Rep. 7, 560 (2017).

54 Rehr, J. J., Albers, R. C. \& Zabinsky, S. I. High-order multiple-scattering calculations of x-rayabsorption fine structure. Phys. Rev. Lett. 69, 3397-3400 (1992).

55 Hutter, J., Iannuzzi, M., Schiffmann, F. \& VandeVondele, J. cp2k: atomistic simulations of condensed matter systems. WIREs Comput. Mol. Sci. 4, 15-25 (2014).

Perdew, J. P., Burke, K. \& Ernzerhof, M. Generalized Gradient Approximation Made Simple. Phys. Rev. Lett. 77, 3865-3868 (1996).

57 Perdew, J. P., Burke, K. \& Ernzerhof, M. Generalized Gradient Approximation Made Simple. Phys. Rev. Lett. 78, 1396 (1997).

58 Grimme, S. Supramolecular Binding Thermodynamics by Dispersion-Corrected Density Functional Theory. Chem. Eur. J. 18, 9955-9964 (2012).

59 Goedecker, S., Teter, M. \& Hutter, J. Separable dual-space Gaussian pseudopotentials. Phys. Rev. B 54, 1703-1710 (1996).

60 VandeVondele, J. et al. Quickstep: Fast and accurate density functional calculations using a mixed Gaussian and plane waves approach. Comput. Phys. Commun. 167, 103-128 (2005). VandeVondele, J. \& Hutter, J. Gaussian basis sets for accurate calculations on molecular systems in gas and condensed phases. J. Chem. Phys. 127, 114105 (2007). Lu, J.-B. et al. Norm-Conserving Pseudopotentials and Basis Sets To Explore Lanthanide Chemistry in Complex Environments. J. Chem. Theory Comput. 15, 5987-5997 (2019). 


\section{Supplementary Information}

\section{Are All Single Atoms Created Equal? Surface Density Dependent Catalytic Activity of Single Pd Atoms Supported on Ceria}

Yongseon Kim ${ }^{1, \|}$, Greg Collinge ${ }^{2,3, \|}$, Mal-Soon Lee ${ }^{2,3}$, Konstantin Khivantsev ${ }^{3}$, Sung June Cho $^{4, *}$, Vassiliki-Alexandra Glezakou ${ }^{2,3}$, Roger Rousseau ${ }^{2,3, *}$, Janos Szanyi ${ }^{3, *}$, Ja Hun Kwak $^{1, *}$

$10{ }^{1}$ Department of Chemical Engineering, Ulsan National Institute of Science and Technology (UNIST), 50 UNIST-gil, Ulsan 44919, Republic of Korea

2 Physical and Computational Sciences Directorate and Institute for Integrated Catalysis, Pacific Northwest National Laboratory, Richland, WA 99354, USA

${ }^{3}$ Institute for Integrated Catalysis, Pacific Northwest National Laboratory, Richland, WA 99352 USA

${ }^{4}$ Department of Chemical Engineering, Chonnam National University, 77 Yongbong-ro, Bukgu, Gwangju 61186, Republic of Korea

“Corresponding authors: sjcho@jnu.ac.kr, roger.rousseau@pnnl.gov,

20 janos.szanyi@pnnl.gov, jhkwak@unist.ac.kr

॥ These authors contributed equally. 


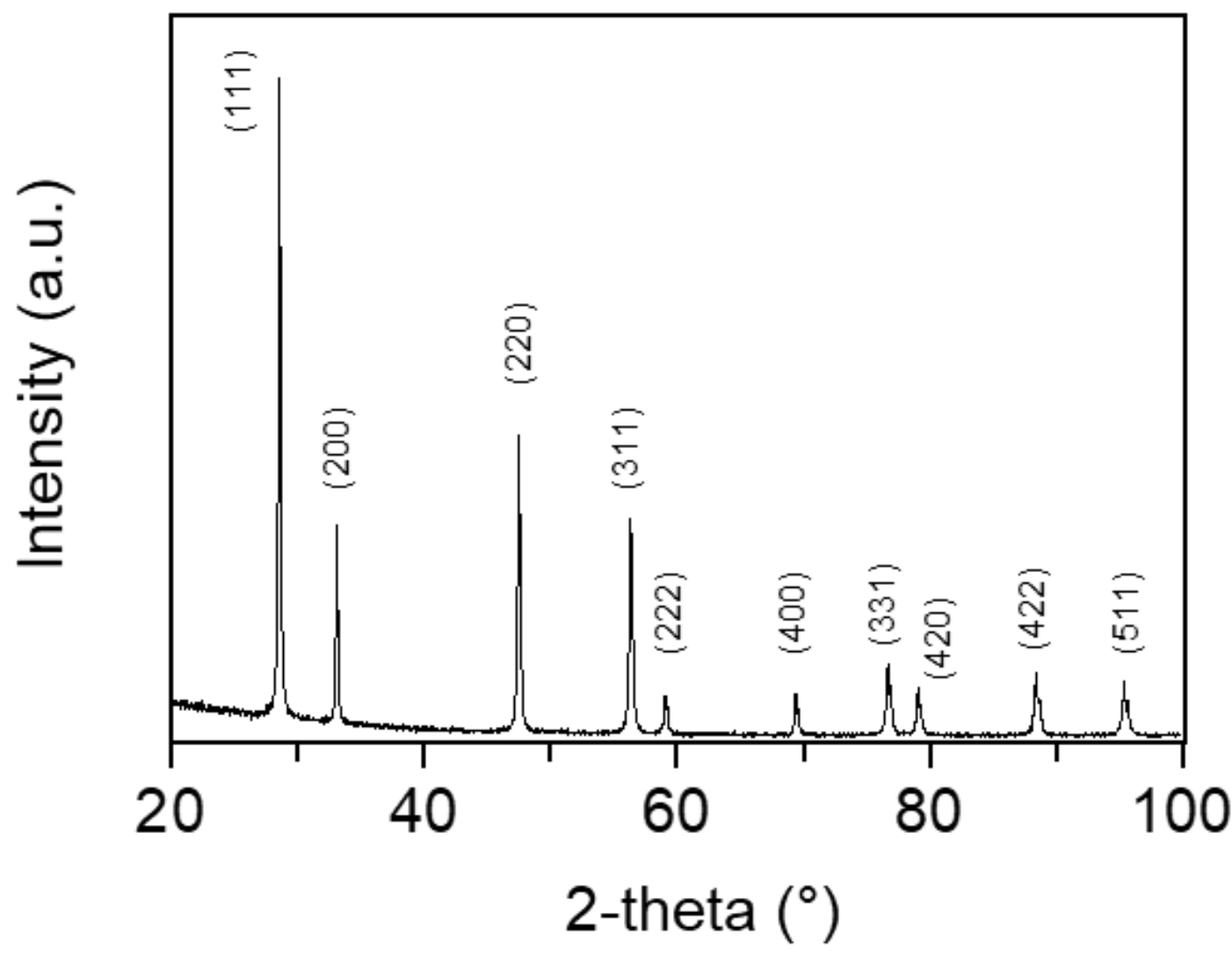

Figure S1. XRD pattern of synthesized $\mathrm{CeO}_{2}$. The $\mathrm{CeO}_{2}$ displays a fluorite cubic structure. 


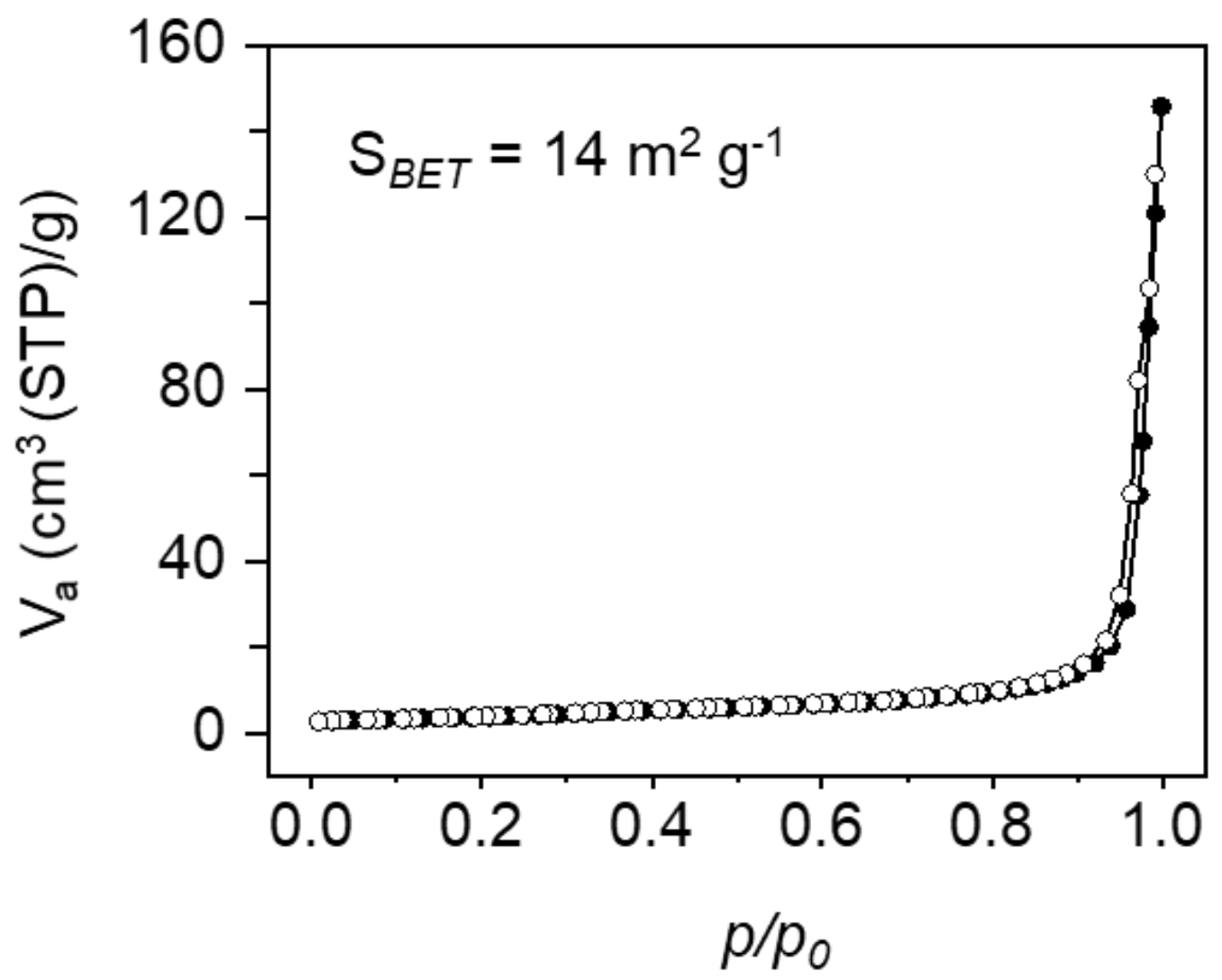

Figure S2. $\mathrm{N}_{2}$ sorption isotherms for $\mathrm{CeO}_{2}$ (Closed circle: adsorption, Open circle: desorption). Brunauer-Emmett-Teller (BET) surface area is $14 \mathrm{~m}^{2} \mathrm{~g}^{-1}$. 


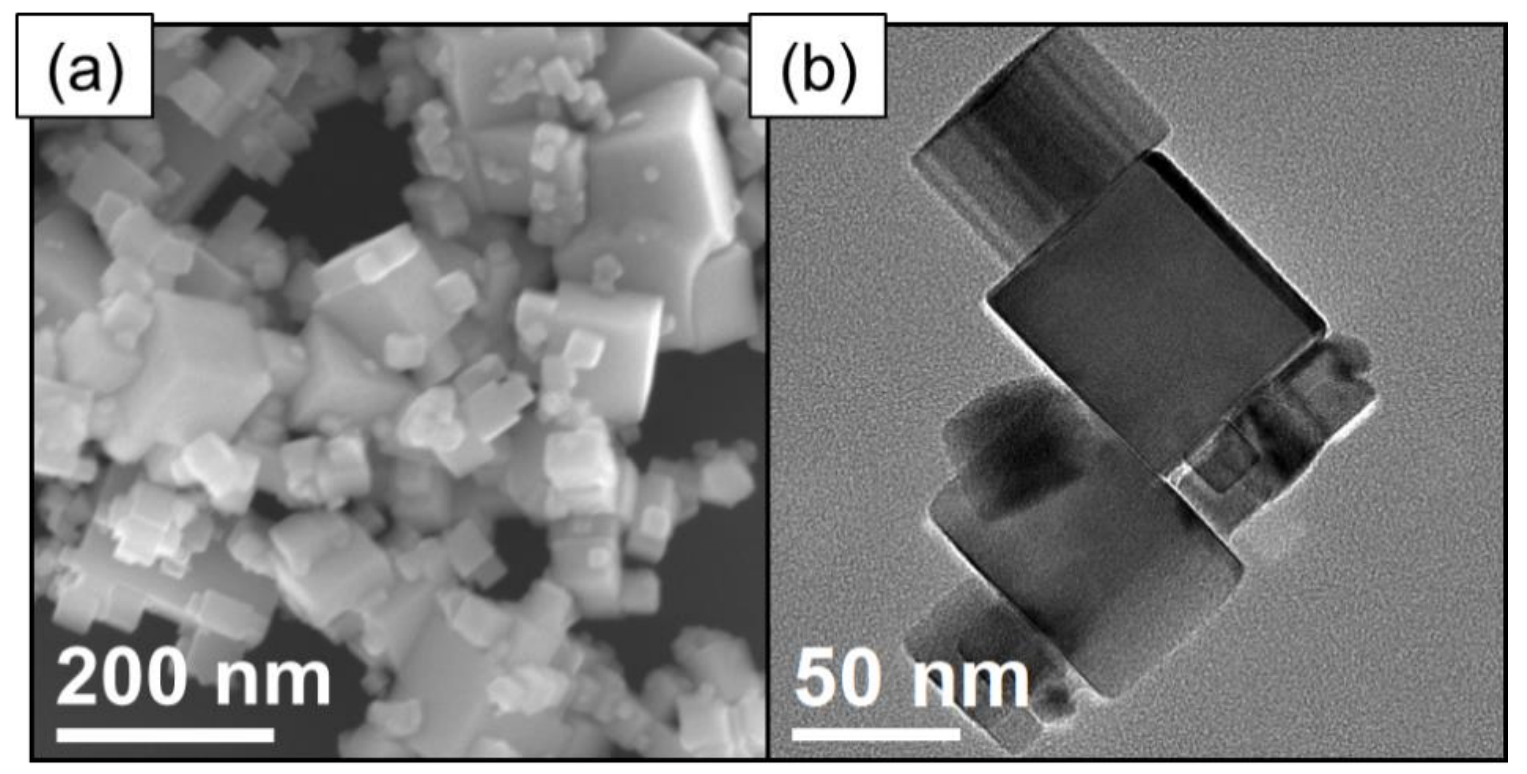

Figure S3. (a) SEM and (b) TEM image of $\mathrm{CeO}_{2}$. The morphology of $\mathrm{CeO}_{2}$ nanoparticles is predominantly cube shaped, exposing mostly (100) surface facets. 

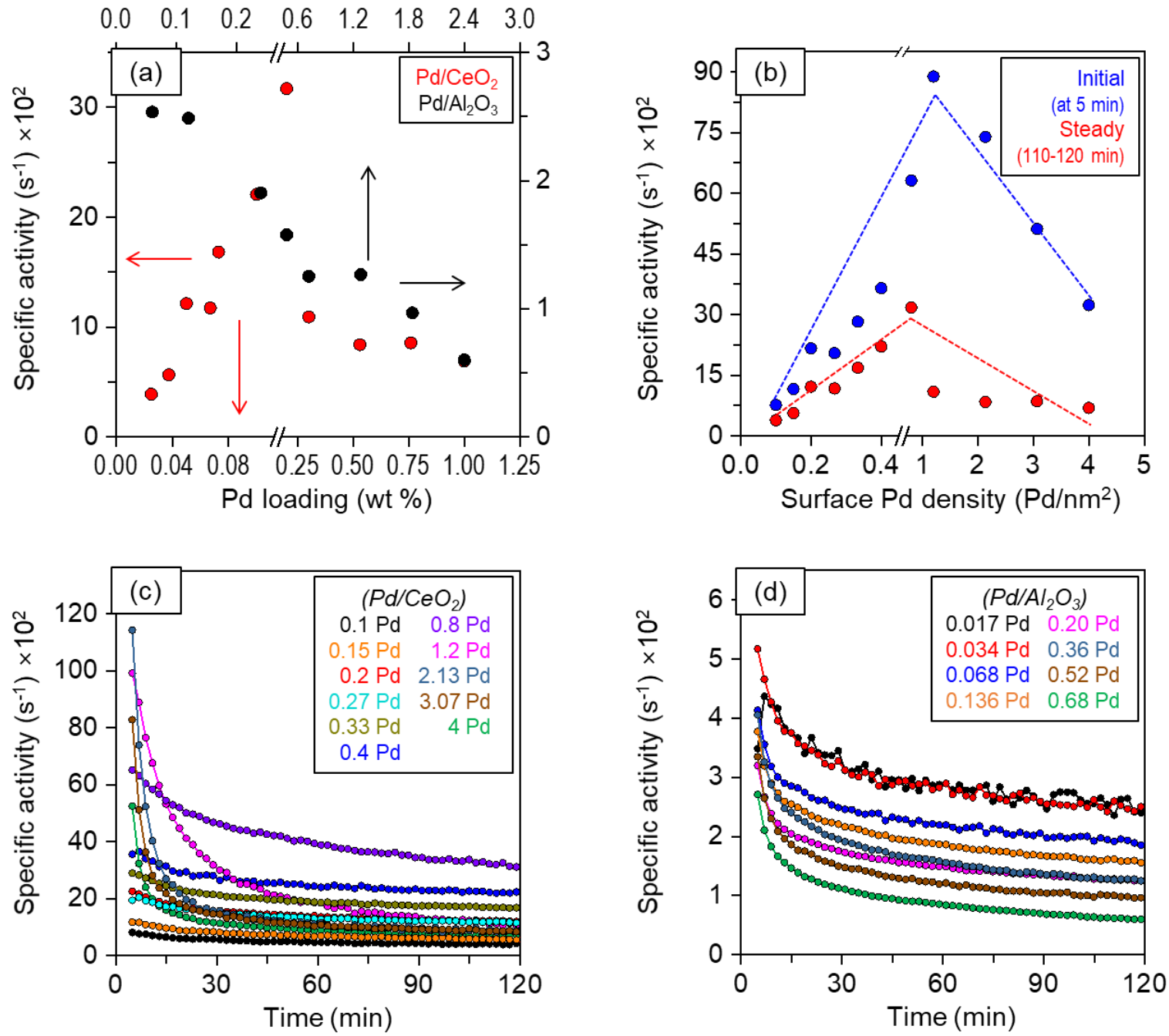

Figure S4. (a) Specific activity of $\mathrm{CO}$ oxidation at steady state as a function of $\mathrm{Pd}$ loading (\%) of $\mathrm{Pd} / \mathrm{CeO}_{2}$ and $\mathrm{Pd} / \mathrm{Al}_{2} \mathrm{O}_{3}$ catalysts, (b) Specific activity of $\mathrm{CO}$ oxidation at initial (5 min, blue colored) and steady state (averaged from 110 to $120 \mathrm{~min}$, red colored) as a function of surface $\mathrm{Pd}$ density of $\mathrm{Pd} / \mathrm{CeO}_{2}$ (trend lines were manually made by observing the trend of the data points). Specific activity of (c) $\mathrm{Pd} / \mathrm{CeO}_{2}$ and (d) $\mathrm{Pd} / \mathrm{Al}_{2} \mathrm{O}_{3}$ as function of time. 


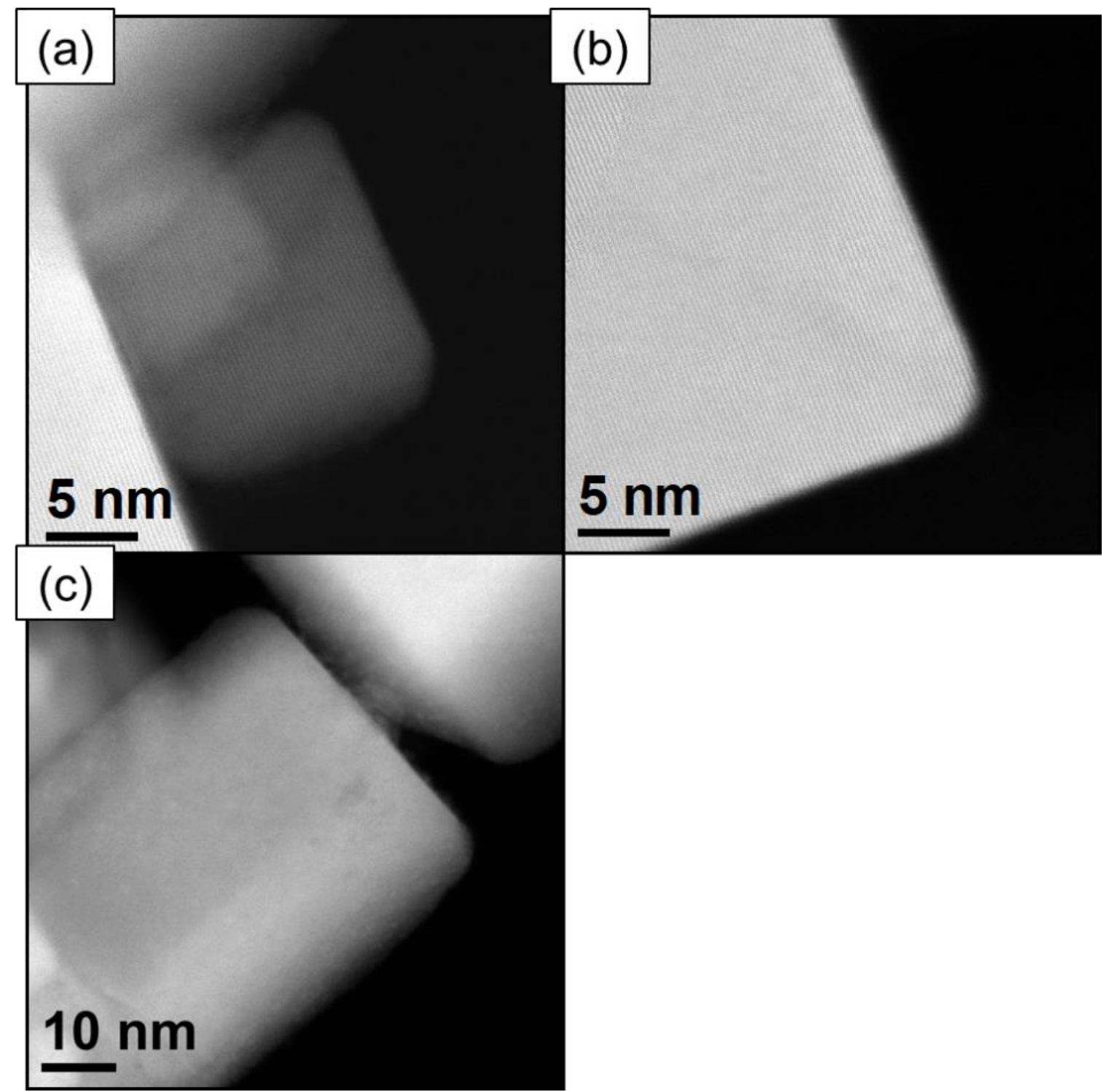

Figure S5. AC-HAADF-STEM images of $(a, b) 0.8 \mathrm{Pd} / \mathrm{CeO}_{2}$ and (c) $4 \mathrm{Pd} / \mathrm{CeO}_{2}$. 


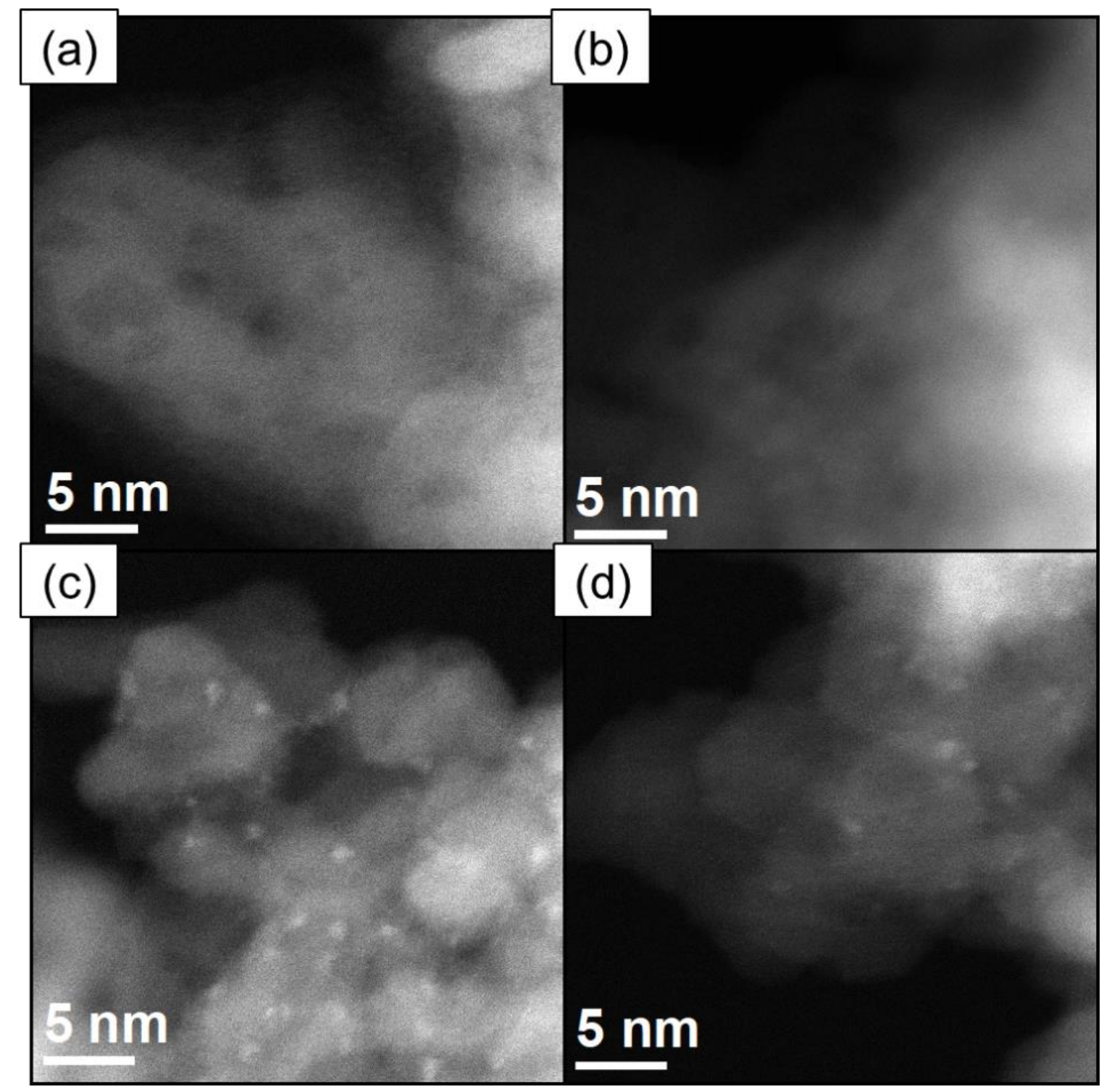

Figure S6. AC-HAADF-STEM images of $(a, b) 0.034 \mathrm{Pd} / \mathrm{Al}_{2} \mathrm{O}_{3}$ and $(c, d) 0.20$ $\mathrm{Pd} / \mathrm{Al}_{2} \mathrm{O}_{3}$. 


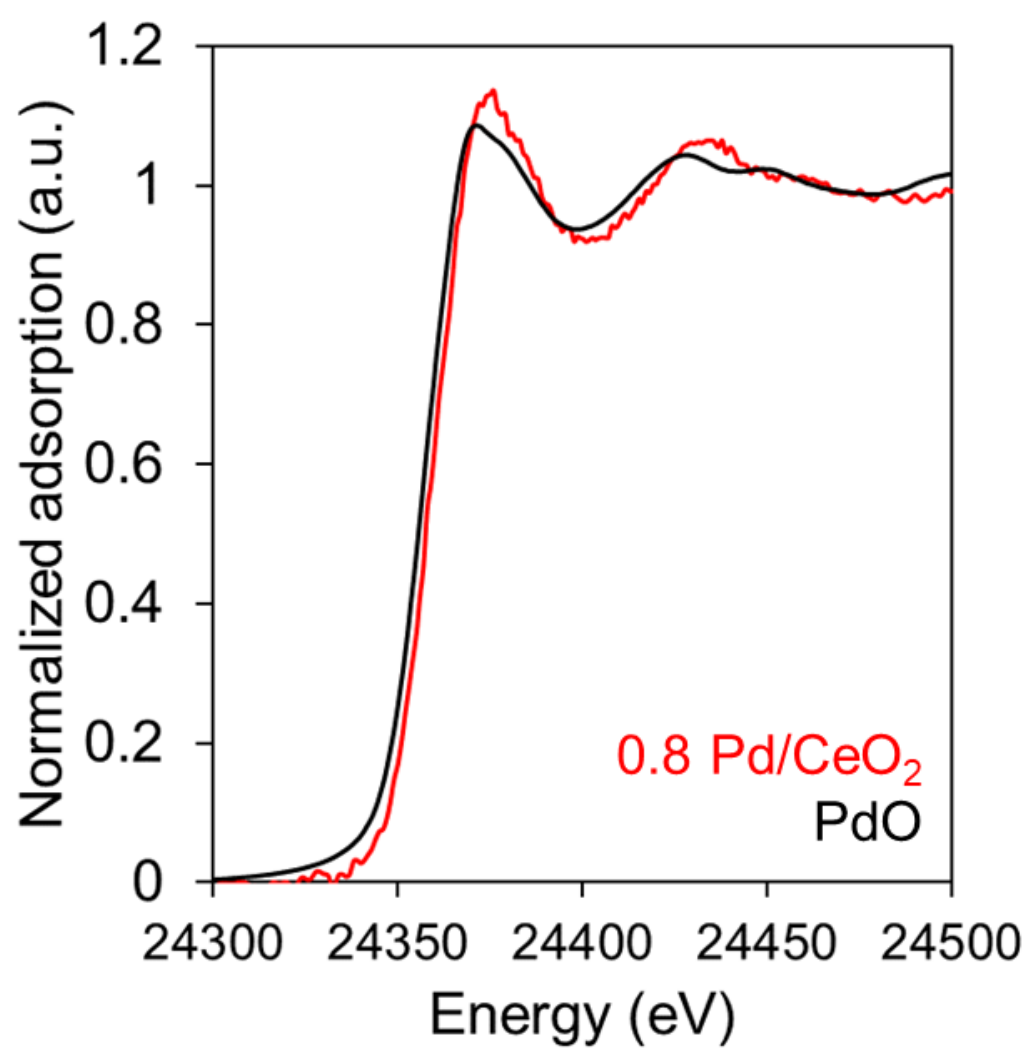

Figure S7. X-ray absorption near edge structure (XANES) spectra of $0.8 \mathrm{Pd} / \mathrm{CeO}_{2}$ and $\mathrm{PdO}$ reference. 

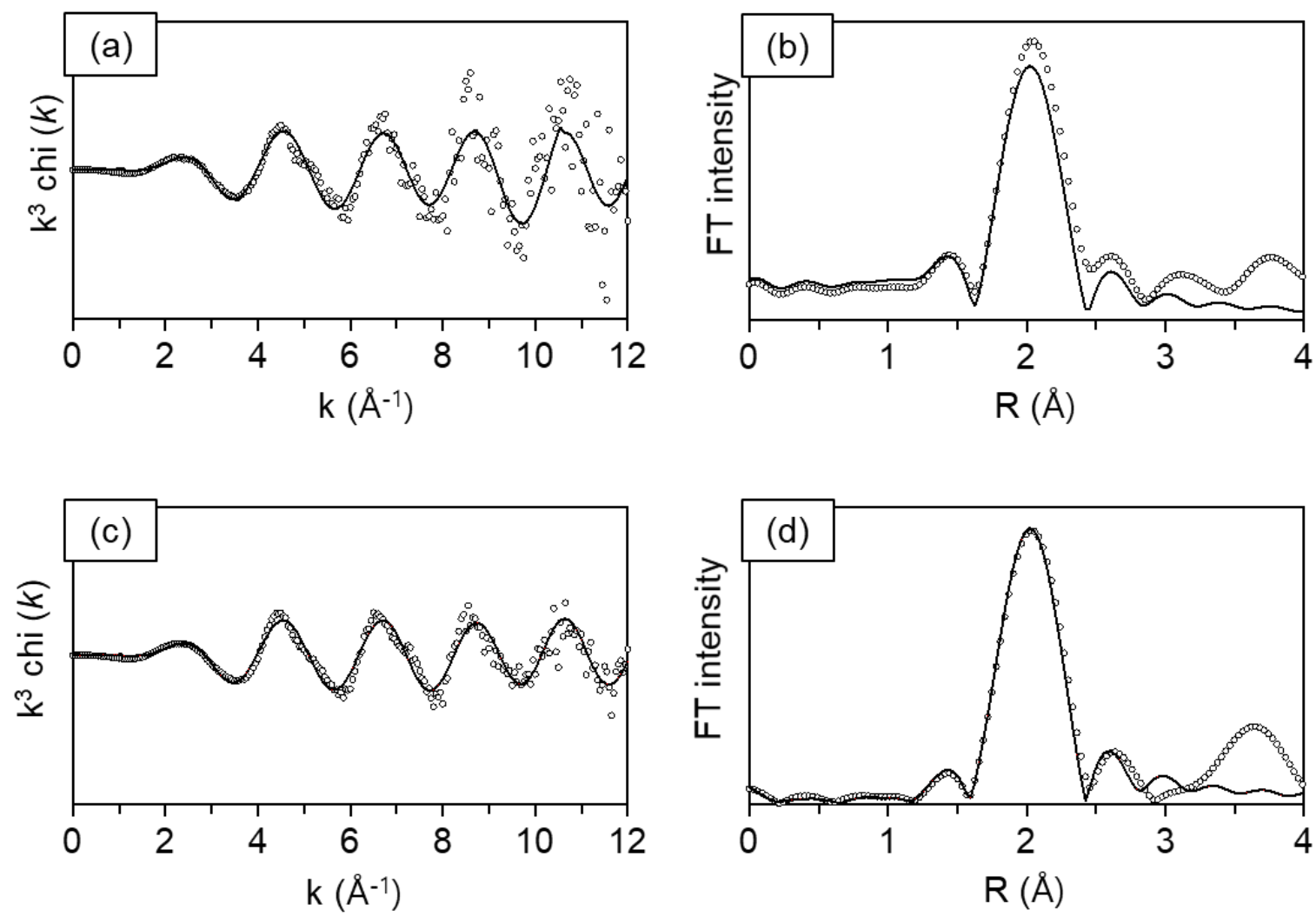

Figure S8. $k^{3}$-weighted chi $(k)$ and the corresponding Fourier transform for $0.8 \mathrm{Pd} / \mathrm{CeO}_{2}(\mathrm{a}, \mathrm{b})$ and $4 \mathrm{Pd} / \mathrm{CeO}_{2}(\mathrm{c}, \mathrm{d})$. The circle and solid line indicate the experimental and fitted spectrum, respectively. The phase shift correction has been made with reference to the $\mathrm{Pd}-\mathrm{O}$ pair. 


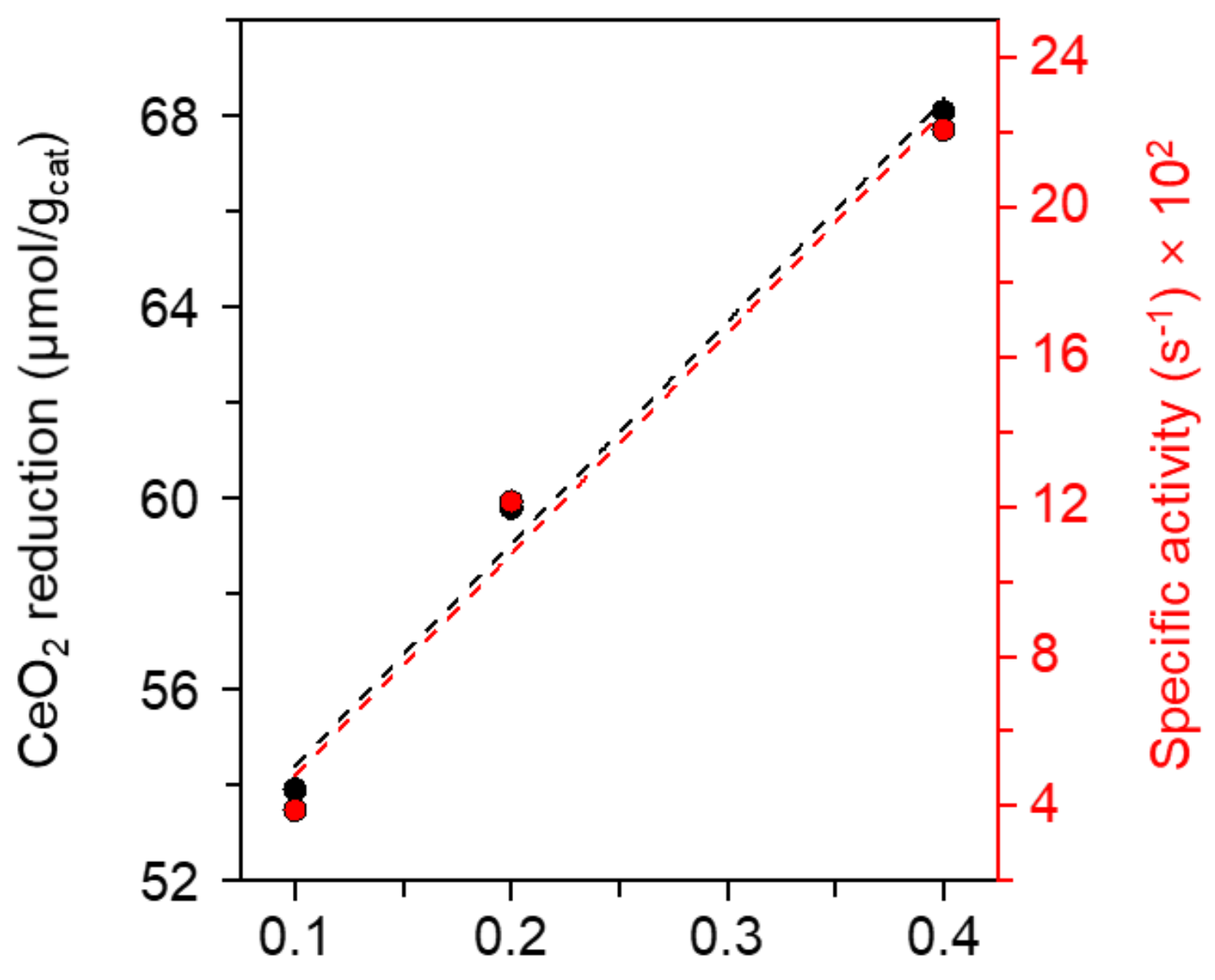

Surface $\mathrm{Pd}$ density $\left(\mathrm{Pd} / \mathrm{nm}^{2}\right)$

Figure S9. Contribution of $\mathrm{CeO}_{2}$ reduction during $\mathrm{H}_{2}$-TPR and specific activity of $\mathrm{Pd} / \mathrm{CeO}_{2}$ as function of surface $\mathrm{Pd}$ density. 


\section{$0.2 \mathrm{Pd} / \mathrm{CeO}_{2} \quad 0.4 \mathrm{Pd} / \mathrm{CeO}_{2} 4 \mathrm{Pd} / \mathrm{CeO}_{2}$}

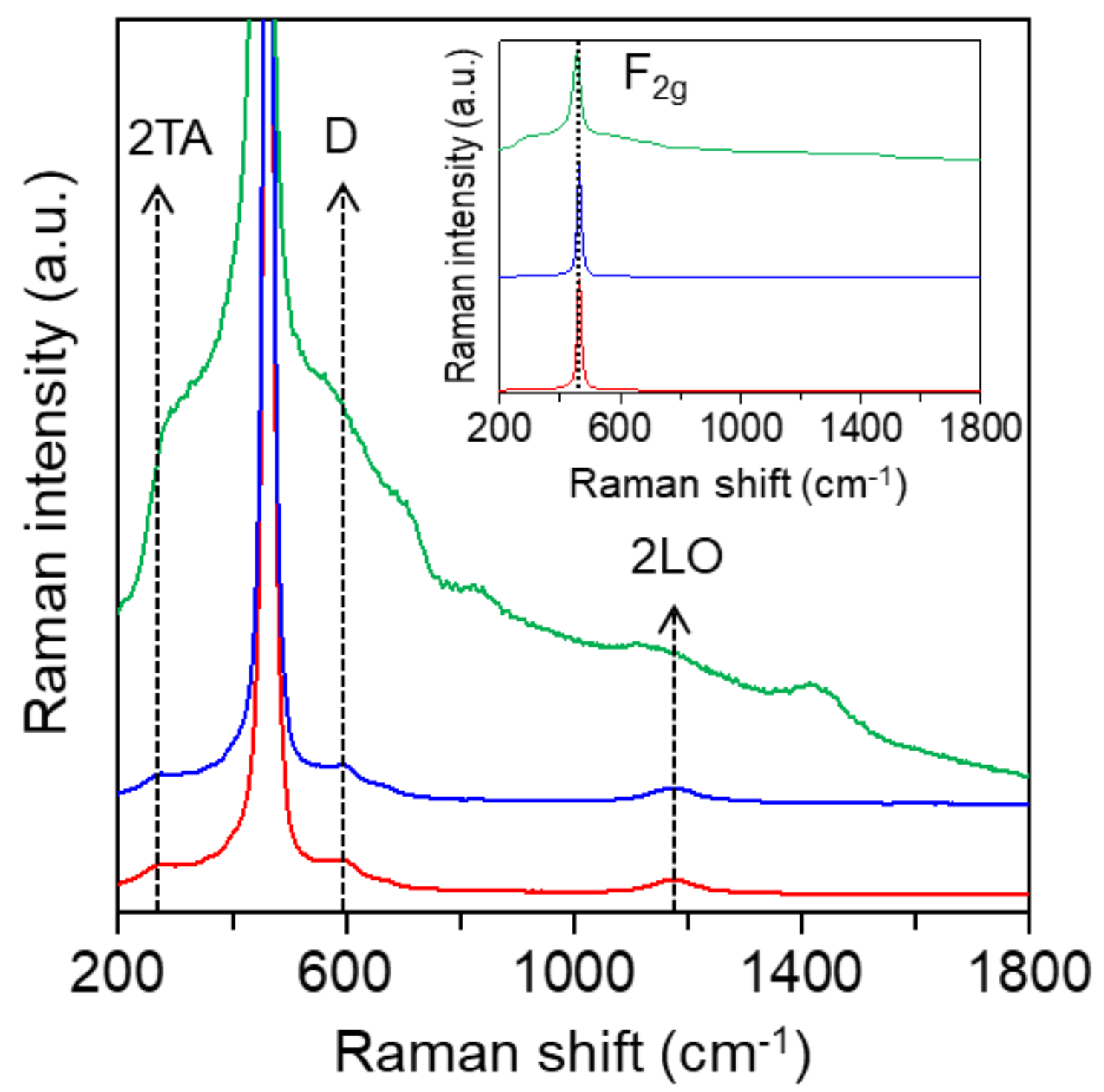

Figure S10. In-situ Raman spectra of $0.2,0.4$ and $4 \mathrm{Pd} / \mathrm{CeO}_{2}$ after pre-treatment.

The spectra were obtained at room temperature and under He flow. Raman intensity was normalized with intensity of $F_{2 g}\left(450-470 \mathrm{~cm}^{-1}\right)$ band. 

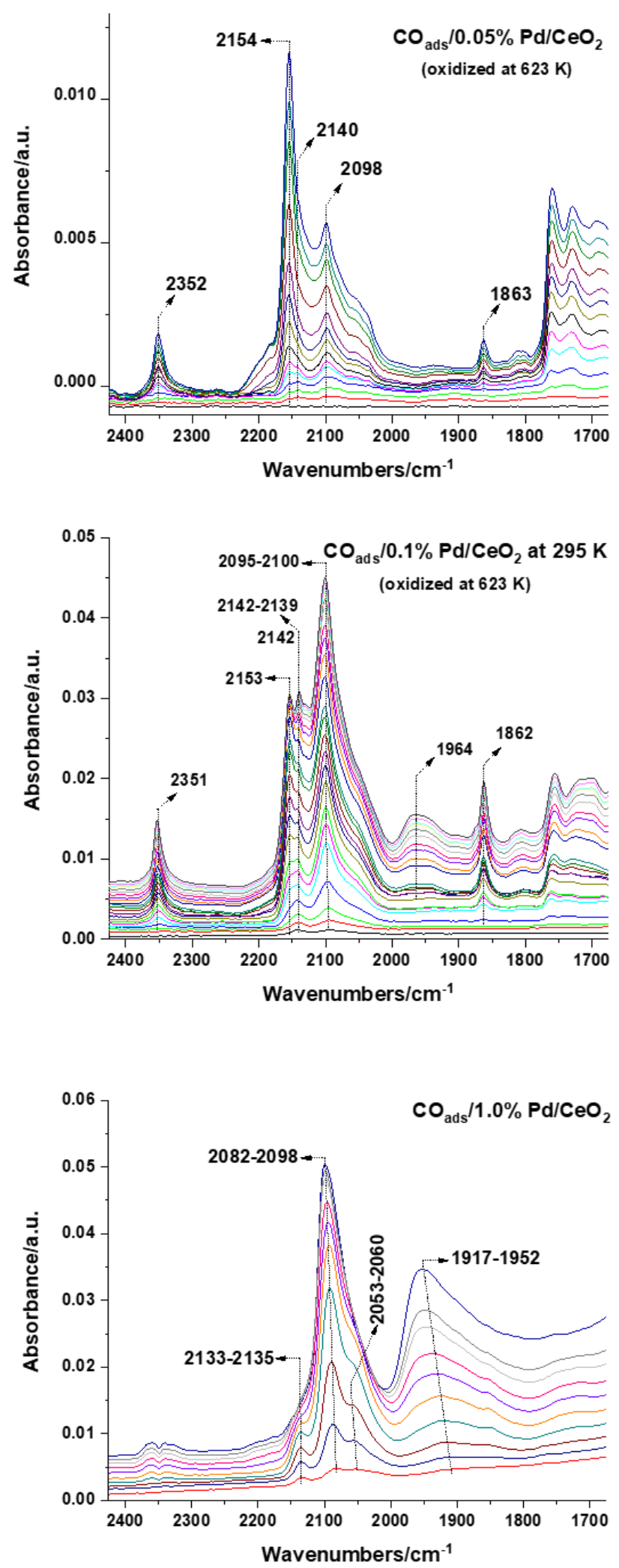

Figure S11. In-situ IR spectra of $0.2,0.4$ and $4 \mathrm{Pd} / \mathrm{CeO}_{2}$. The spectra were obtained during absorbing $\mathrm{CO}$ on oxidized catalysts. 


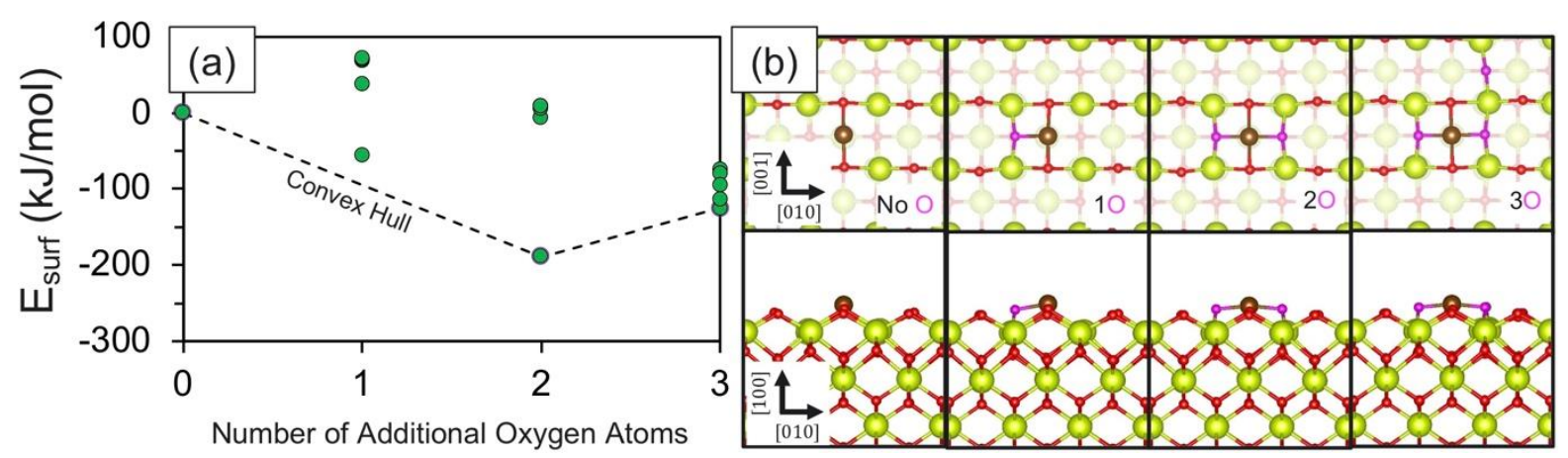

Figure S12. (a) DFT surface energy of the $\mathrm{Pd}_{1} / \mathrm{CeO} 2(100)$ model, seen in the first panel of (b), as a function of the number of additional $\mathrm{O}$ atoms adsorbed to the surface at nearby $\mathrm{Ce}$ bridge sites. (b) Minimum energy $\mathrm{O}$ adsorption configuration for each $\mathrm{O}$ atom addition.

Green and red atoms are $\mathrm{Ce}$ and $\mathrm{O}$ of $\mathrm{CeO}_{2}$, respectively; brown and magenta atoms are $\mathrm{Pd}$ and $\mathrm{O}$ of $\left(\mathrm{PdO}_{\mathrm{x}}\right)_{1}$.

In Figure S12, we computed the $0 \mathrm{~K}$ DFT surface energy defined as:

$$
\mathrm{E}_{\text {surf }}\left[\mathrm{N}_{\mathrm{O}}\right]=\mathrm{E}_{\left(\mathrm{PdO}_{\mathrm{x}}\right) / \mathrm{CeO}_{2}(100)}\left[\mathrm{N}_{\mathrm{O}}\right]-\mathrm{E}_{\mathrm{Pd} / \mathrm{CeO}_{2}(100)}[0]-\mathrm{N}_{\mathrm{O}}\left(\frac{1}{2} \mathrm{E}_{\mathrm{O}_{2}(\mathrm{~g})}\right)
$$

where $\mathrm{E}_{\mathrm{Pd} / \mathrm{CeO}_{2}(100)}\left[\mathrm{N}_{\mathrm{O}}\right]$ is the total DFT energy of the $(6 \times 6) \mathrm{Pd} / \mathrm{CeO}_{2}(100)$ supercell with

$10 \mathrm{~N}_{\mathrm{O}}$ additional oxygen adatoms present, and $\mathrm{E}_{\mathrm{O}_{2}(\mathrm{~g})}$ is the DFT calculated energy of an $\mathrm{O}_{2}$ molecule in the gas phase. The slopes connecting the lowest $\mathrm{E}_{\text {surf }}\left[\mathrm{N}_{\mathrm{O}}\right]$ to the lowest $\mathrm{E}_{\text {surf }}\left[\mathrm{N}_{\mathrm{O}}-1\right]$ provides an estimate of the chemical potential to create the structure corresponding to $\mathrm{E}_{\text {surf }}\left[\mathrm{N}_{\mathrm{O}}\right]$. To be stable, the states thus connected must have a positive curvature (i.e. constantly increasing slope), which is not the case for any of the points at

$15 \mathrm{E}_{\text {surf }}[1]$. This results in a very large negative $(0 \mathrm{~K})$ chemical potential $(\sim-95 \mathrm{~kJ} / \mathrm{mol} / \mathrm{O})$ for the minimum energy structure at $\mathrm{E}_{\text {surf }}[2]$ with the minimum energy structure at $\mathrm{E}_{\text {surf }}[3]$ only accessible when the $(0 \mathrm{~K})$ chemical potential increases to $\sim+63 \mathrm{~kJ} / \mathrm{mol}$, a greater than 150 $\mathrm{kJ} / \mathrm{mol} / \mathrm{O}$ difference. Therefore, if a relatively modest partial pressure of $\mathrm{O}_{2}$ is applied so as to accomplish any $\mathrm{O}$ adsorption, which is almost certainly the case during catalyst synthesis, 20 only the $\left(\mathrm{PdO}_{2}\right)_{1}$ structure (shown in the third panel of Figure $\mathrm{S} 12 \mathrm{~b}$ ) will be stable. The other structures at $\mathrm{N}_{\mathrm{O}}=2$, where the second $\mathrm{O}$ adsorbs in nearby Ce-Ce bridge sites, are too high in energy compared to the minimum energy structure to be stably formed. As noted, a large increase in the applied chemical potential is required to access the minimum energy structure at $\mathrm{E}_{\text {surf }}[3]$. This strongly suggests that the active sites in $\mathrm{Pd} / \mathrm{CeO}_{2}(100)$ are $\left(\mathrm{PdO}_{2}\right)_{1}$ units, and so this structure was chosen for continued analysis. 

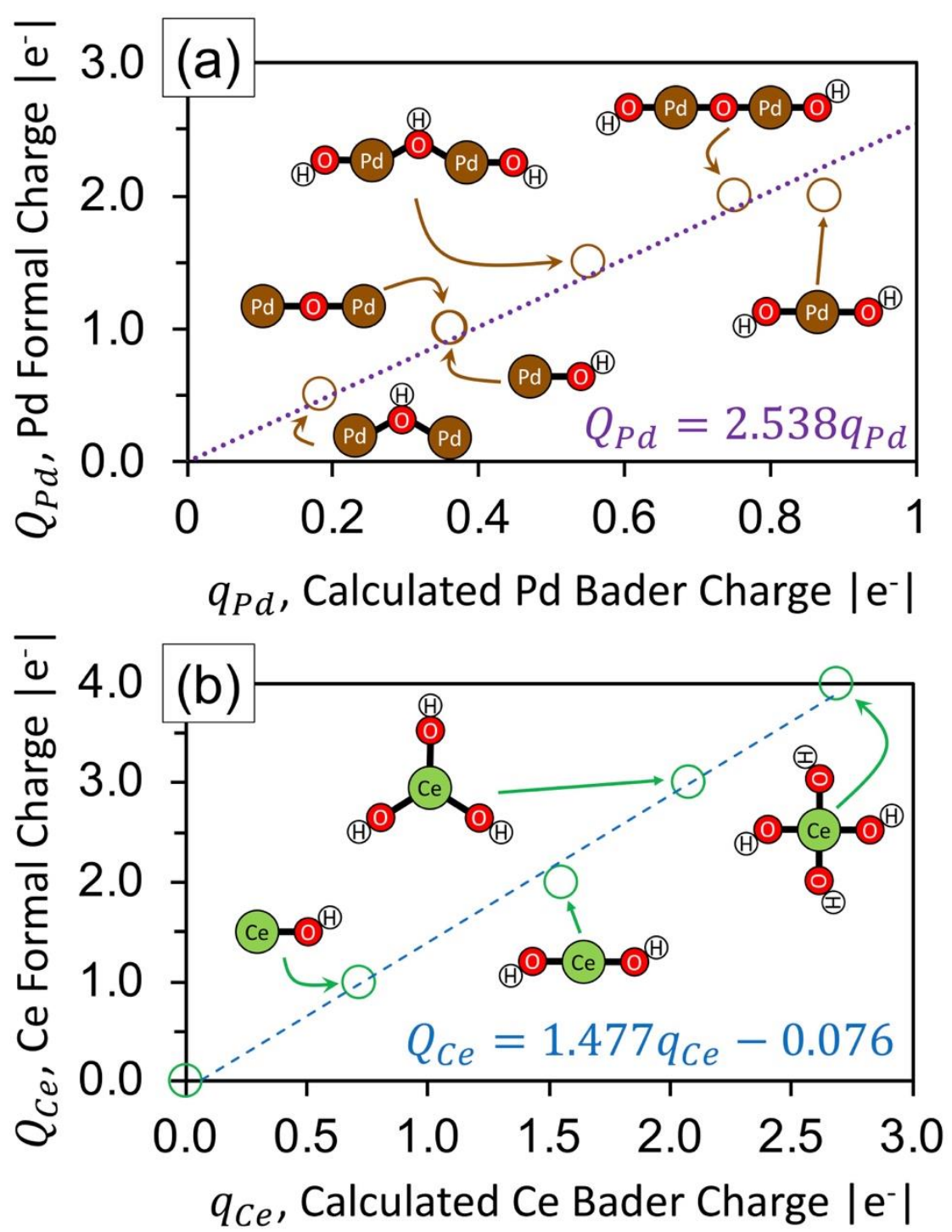

Figure S13. Bader charge calibrations for (a) Pd and (b) Ce. Each data point represents a metal-hydroxide, metal-oxo, or mixed metal oxo/hydroxide complex with a known formal charge. Bader charges were then assessed using the computational methods employed in the rest of the work.

To assess the charge state of the active site, we performed a Bader-partitioning of both the electron and spin density of the $\left(\mathrm{PdO}_{2}\right)_{1} / \mathrm{CeO}_{2}(100)$ system. The electron density Bader charges of $\mathrm{Pd}$ and Ce were additionally calibrated against known metal complexes' oxidation states (see Figure S13) to permit the assignment of formal charges. By then comparing, in aggregate, computed formal charges with the spin density Bader charges (see Table S1), we can accurately infer the charge state of each atom in our system. Using this method, we are able to determine $\mathrm{Pd}$ to be in an overoxidized $>+2$ state. This overoxidation occurs due to the presence of the two additional $\mathrm{O}$ atoms forming $\left(\mathrm{PdO}_{2}\right)_{1}$. As shown schematically in Figure $\mathrm{S} 13$, to balance a $\mathrm{Pd}^{2+}$, these two $\mathrm{O}$ atoms (which will become $\mathrm{O} 1$ and $\mathrm{O} 2$ in Figure $4 \mathrm{a}$ of the main text upon adsorption) would need to be $\mathrm{O}^{1-}$ radicals, which is a very unfavorable electron configuration. This unfavorability is alleviated, to a degree, by abstracting charge from the two adjacent $\mathrm{O}$ atoms of the $\mathrm{CeO}_{2}(100)$ surface $(\mathrm{O} 3$ and $\mathrm{O} 4$ in Figure $4 \mathrm{a}$ of the main text), but this can only bring each $\mathrm{O}$ atom (O1 through $\mathrm{O} 4)$ to a formal -1.5 charge state. To further alleviate their unfavorable electron configurations, the four $O$ atoms, overoxidize Pd past +2 -producing a computed $+2.58 \mathrm{Pd}$ oxidation state-to achieve 
$-1.65 O$ charge states in the final structure. Spin density Bader charges confirm the undersaturation of $\mathrm{O}$ atoms as each $\mathrm{O}$ atom has a clear non-zero net unpaired electron density (see Table S1). The spin bader charge on Pd is computed to be zero, but visual inspection of the spin density around $\mathrm{Pd}$ (Figure $4 \mathrm{~b}$ of the main text) shows two d-orbital lobes both clearly containing net unpaired electron density but with opposite spins, leading to the overall net zero unpaired charge that we have computed in Table S1. Thus, we have confidence in the assignment of $>+2$ for Pd based on the Bader partitioning of electron density and Bader calibration curve shown in Figure S13.

Table S1. Summary of calculated excess Bader charge (to the nearest hundredth $\left|e^{-}\right|$) on atoms nearby $\mathrm{Pd}$ in the $\left[\mathrm{PdO}_{4}\right]$ active site as compared to atoms far away. $\mathrm{O}$ atom labels refer to those in Figure $4 a$ of the main text.

\begin{tabular}{|c|c|c|c|}
\hline Atom & $\begin{array}{c}\text { Bader Charge } \\
\left(\mathrm{e}^{-}\right)\end{array}$ & $\begin{array}{c}\text { Oxidation State } \\
\left(\mathrm{e}^{-}\right)\end{array}$ & $\begin{array}{c}\text { Unpaired Bader } \\
\text { Charge }\left(\left|\mathrm{e}^{-}\right|\right)\end{array}$ \\
\hline $\mathrm{Pd}$ & 1.02 & +2.58 & 0.00 \\
\hline $\begin{array}{l}\text { Surface } \mathrm{O} \text { of } \\
\mathrm{CeO}_{2}(100)\end{array}$ & -1.12 to -1.13 & $-2.00^{a}$ & $0.00-0.01$ \\
\hline 01 & -0.92 & -1.65 & 0.29 \\
\hline $\mathrm{O} 2$ & -0.92 & -1.65 & 0.28 \\
\hline $\mathrm{O} 3$ & -0.91 & -1.65 & 0.34 \\
\hline $\mathrm{O} 4$ & -0.91 & -1.65 & 0.34 \\
\hline O5 & -1.10 & $-2.0^{a}$ & 0.01 \\
\hline 06 & -1.10 & $-2.0^{a}$ & 0.01 \\
\hline 07 & -1.10 & $-2.0^{a}$ & 0.01 \\
\hline $\mathrm{O} 8$ & -1.10 & $-2.0^{a}$ & 0.01 \\
\hline $\begin{array}{l}\text { Surface Ce of } \\
\mathrm{CeO}_{2}(100)\end{array}$ & $2.32-2.41$ & $3.35-3.44\left(4.0^{\mathrm{a}}\right)$ & 0.00 \\
\hline $\mathrm{Ce} 1$ & 2.41 & $3.42\left(4.0^{\mathrm{a}}\right)$ & 0.02 \\
\hline Ce2 & 2.40 & $3.47\left(4.0^{\mathrm{a}}\right)$ & 0.02 \\
\hline Ce3 & 2.38 & $3.49\left(4.0^{\mathrm{a}}\right)$ & 0.02 \\
\hline Ce4 & 2.37 & $3.44\left(4.0^{\mathrm{a}}\right)$ & 0.02 \\
\hline
\end{tabular}

a Assigned based on charge balance and/or comparison to the bulk $\mathrm{CeO}_{2}$ Bader charges in the same model. Bulk $\mathrm{Ce}^{4+}$ have an average Bader charge and average calibrated oxidation state of $2.44 \pm 0.02$ and $3.52 \pm 0.04$, respectively. 


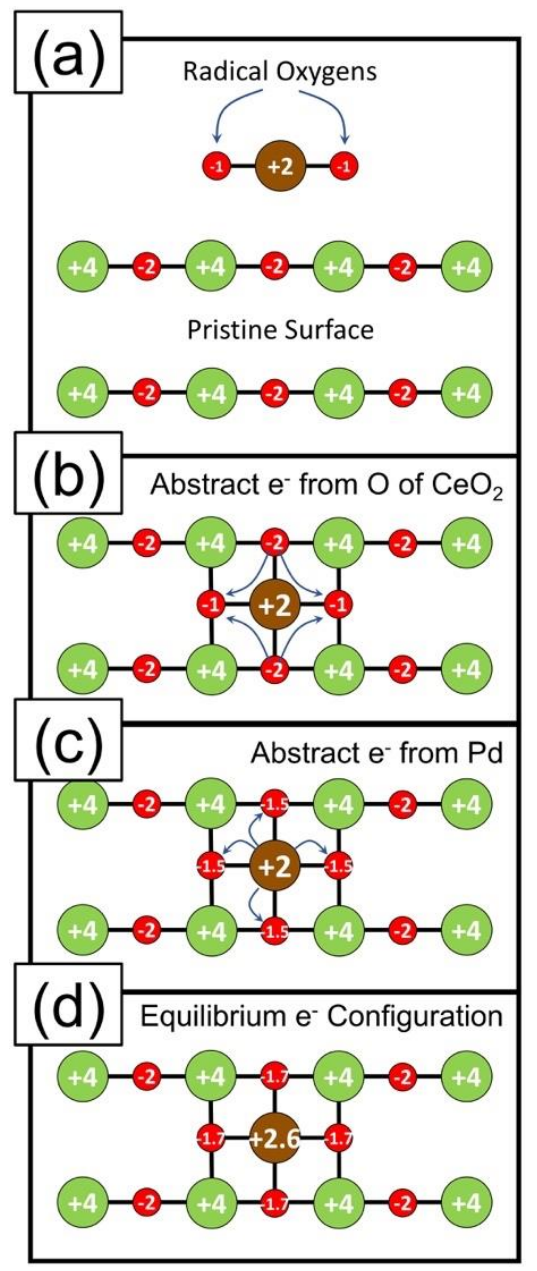

Figure S14. Illustration of how the $\left[\mathrm{PdO}_{4}\right]$ active site is overoxidized. Brown, green, and red circles represent $\mathrm{Pd}, \mathrm{Ce}$, and $\mathrm{O}$ atoms, respectively. 


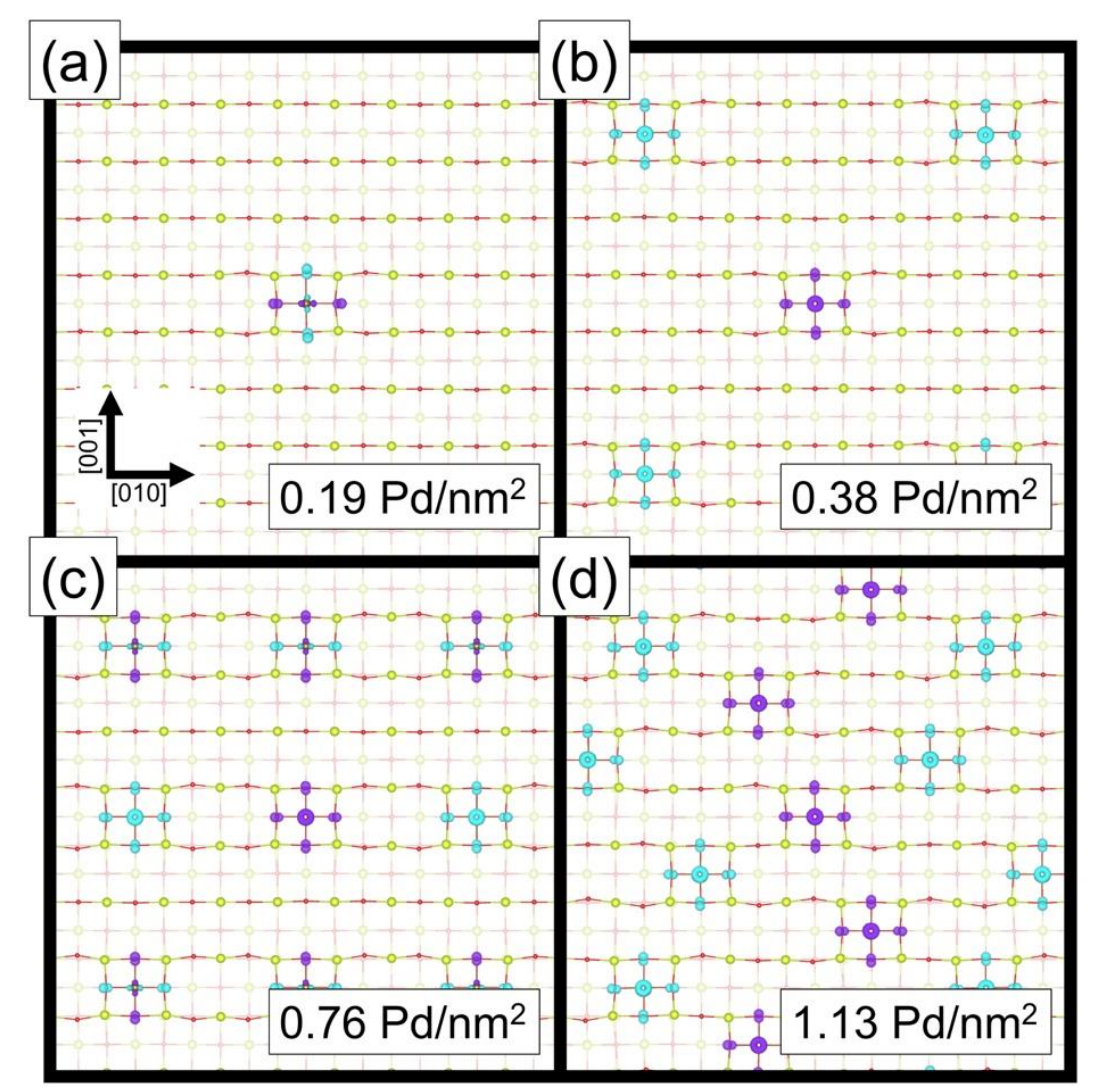

Figure S15. Spin density plots of the $\left(\mathrm{PdO}_{2}\right)_{1} / \mathrm{CeO}_{2}(100)$ system showing the chemical similarity and distribution of active sites in each model constructed to produce surface $\mathrm{Pd}$ densities of (a) 0.19 , (b) 0.38 , (c) 0.76 , and (d) $1.13 \mathrm{Pd} / \mathrm{nm}^{2}$. Spin up and spin down density contours are shown in purple and blue shading, respectively. The relative size of each atom has been reduced to aid the eye, but the color scheme is identical to that used in Figure S12 (isosurface level $=0.04\left|\mathrm{e}^{-}\right| / \mathrm{Bohr}^{3}$, which is approximately $1 / 5$ the maximum spin density) 

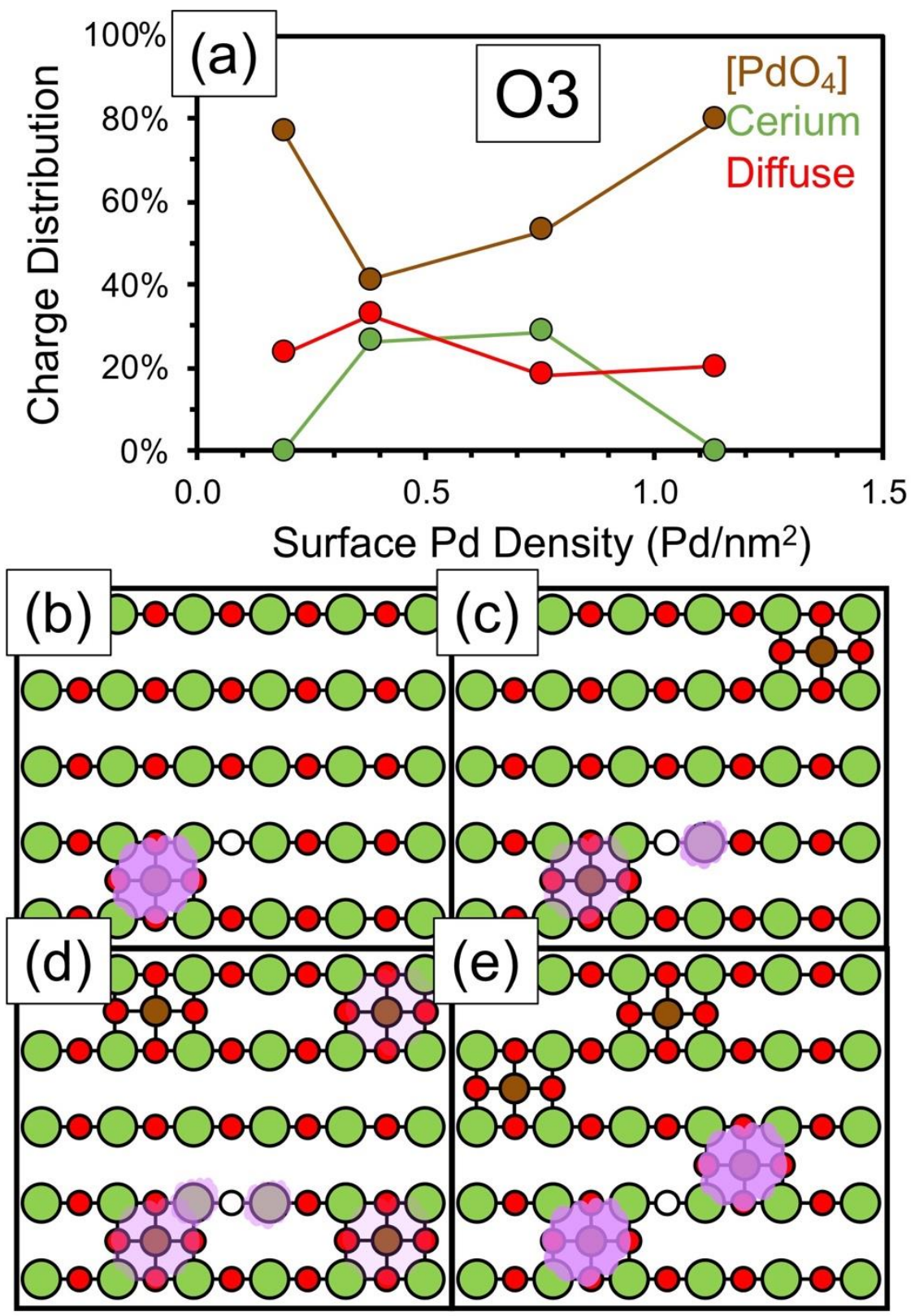

Figure S16. (a) Percent distribution of excess charge left behind after reduction of the $\mathrm{O}$ atom occupying $\mathrm{O} 3$ site. (b) - (e) A schematic showing where charge was found to be localized (purple clouds; darker purple = more electron density) at surface Pd densities of (b) $0.19 \mathrm{Pd} / \mathrm{nm}^{2}$, (c) $0.38 \mathrm{Pd} / \mathrm{nm}^{2}$, (d) $0.76 \mathrm{Pd} / \mathrm{nm}^{2}$, and (e) $1.13 \mathrm{Pd} / \mathrm{nm}^{2}$. Brown, green, and red circles represent $\mathrm{Pd}, \mathrm{Ce}$, and $\mathrm{O}$ atoms, respectively. 

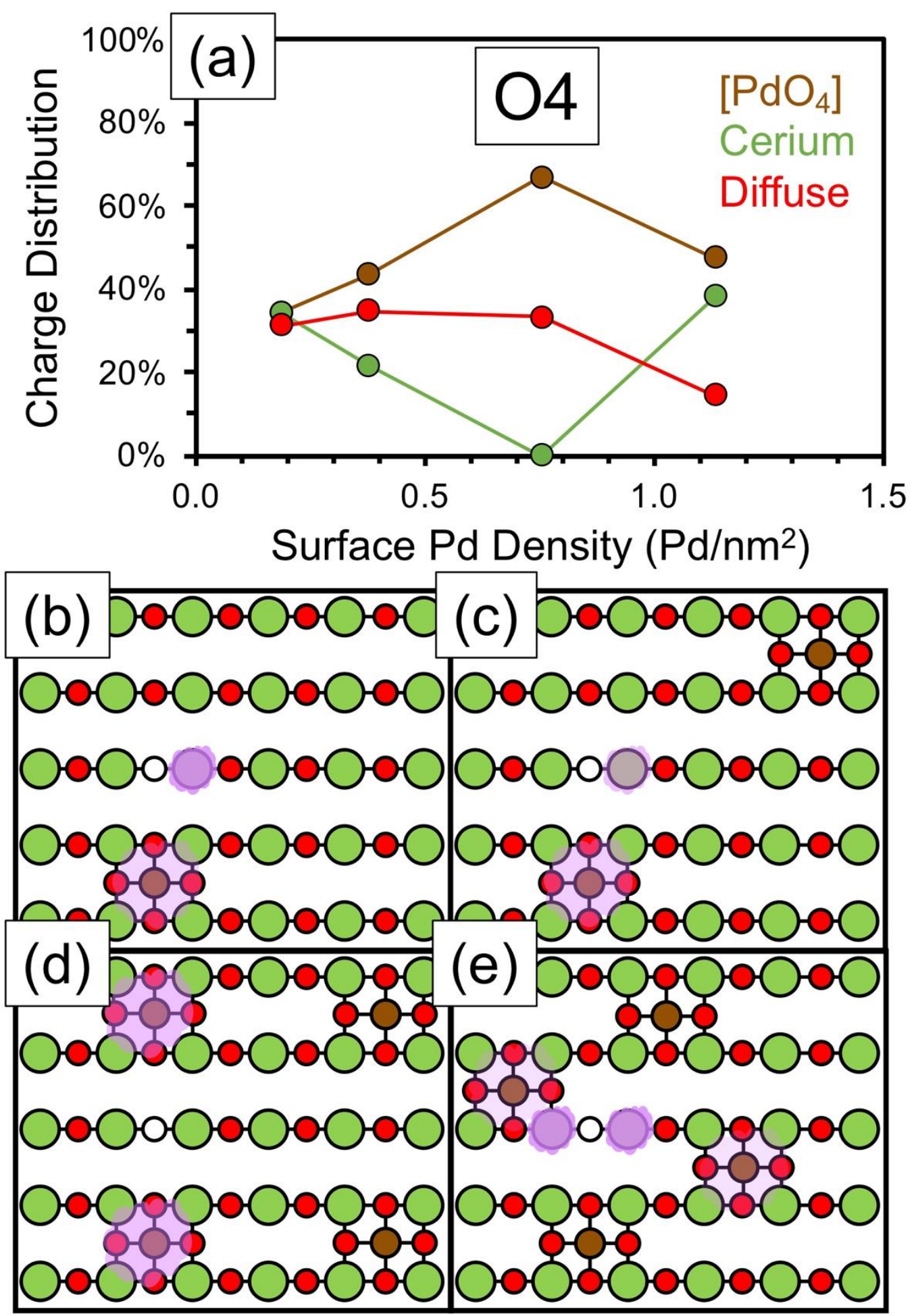

Figure S17. (a) Percent distribution of excess charge left behind after reduction of the $\mathrm{O}$ atom occupying $\mathrm{O}$ site 4. (b) - (e) A schematic showing where charge was found to be localized (purple clouds; darker purple = more electron density) at surface Pd densities of (b) $0.19 \mathrm{Pd} / \mathrm{nm}^{2}$, (c) $0.38 \mathrm{Pd} / \mathrm{nm}^{2}$, (d) $0.76 \mathrm{Pd} / \mathrm{nm}^{2}$, and (e) $1.13 \mathrm{Pd} / \mathrm{nm}^{2}$. Brown, green, and red circles represent $\mathrm{Pd}, \mathrm{Ce}$, and $\mathrm{O}$ atoms, respectively. 

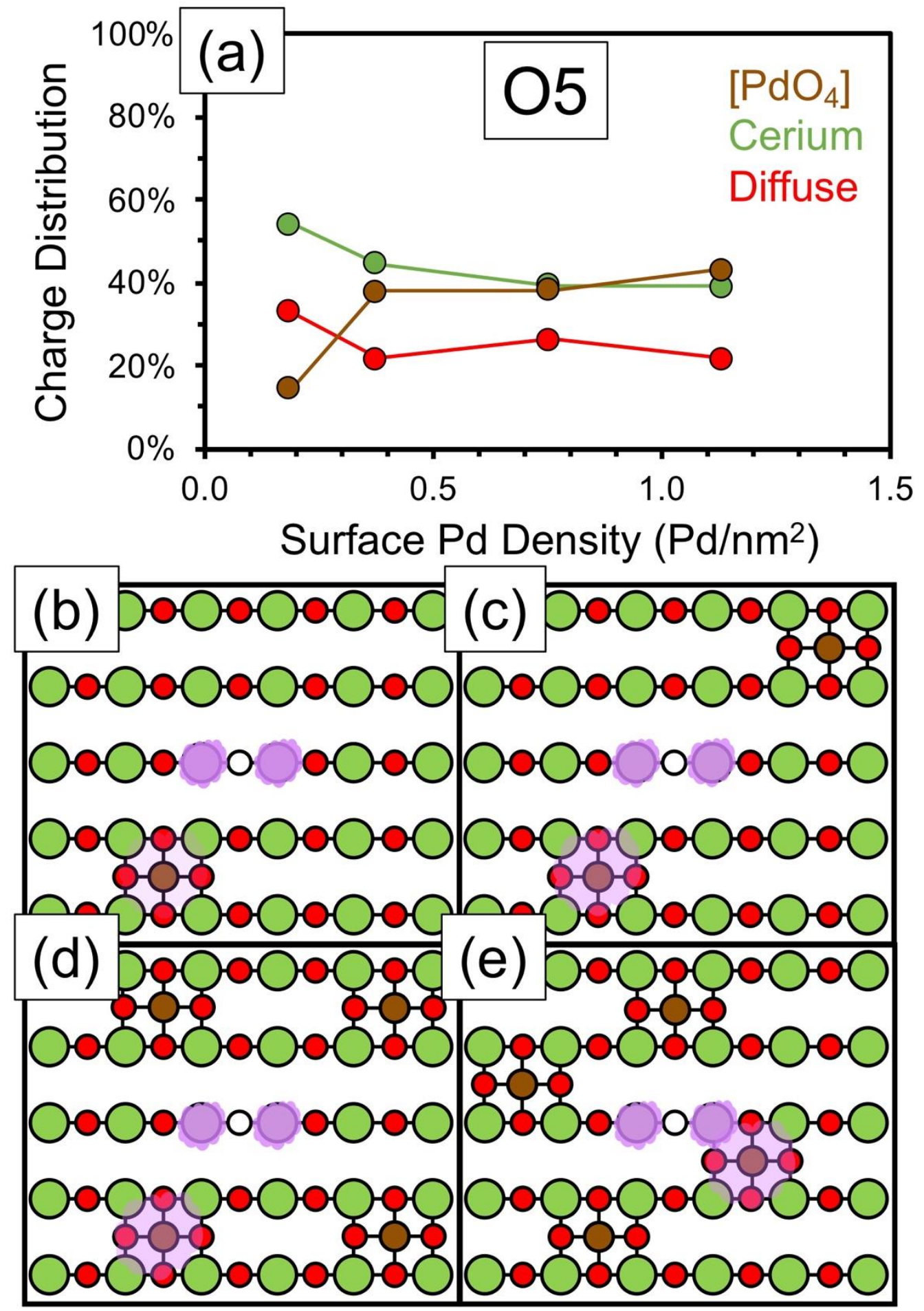

Figure S18. a) Percent distribution of excess charge left behind after reduction of the $\mathrm{O}$ atom occupying $\mathrm{O}$ site 5 . (b) - (e) A schematic showing where charge was found to be localized (purple clouds; darker purple = more electron density) at surface $\mathrm{Pd}$ densities of (b) $0.19 \mathrm{Pd} / \mathrm{nm}^{2}$, (c) $0.38 \mathrm{Pd} / \mathrm{nm}^{2}$, (d) $0.76 \mathrm{Pd} / \mathrm{nm}^{2}$, and (e) $1.13 \mathrm{Pd} / \mathrm{nm}^{2}$. Brown, green, and red circles represent $\mathrm{Pd}, \mathrm{Ce}$, and $\mathrm{O}$ atoms, respectively. 

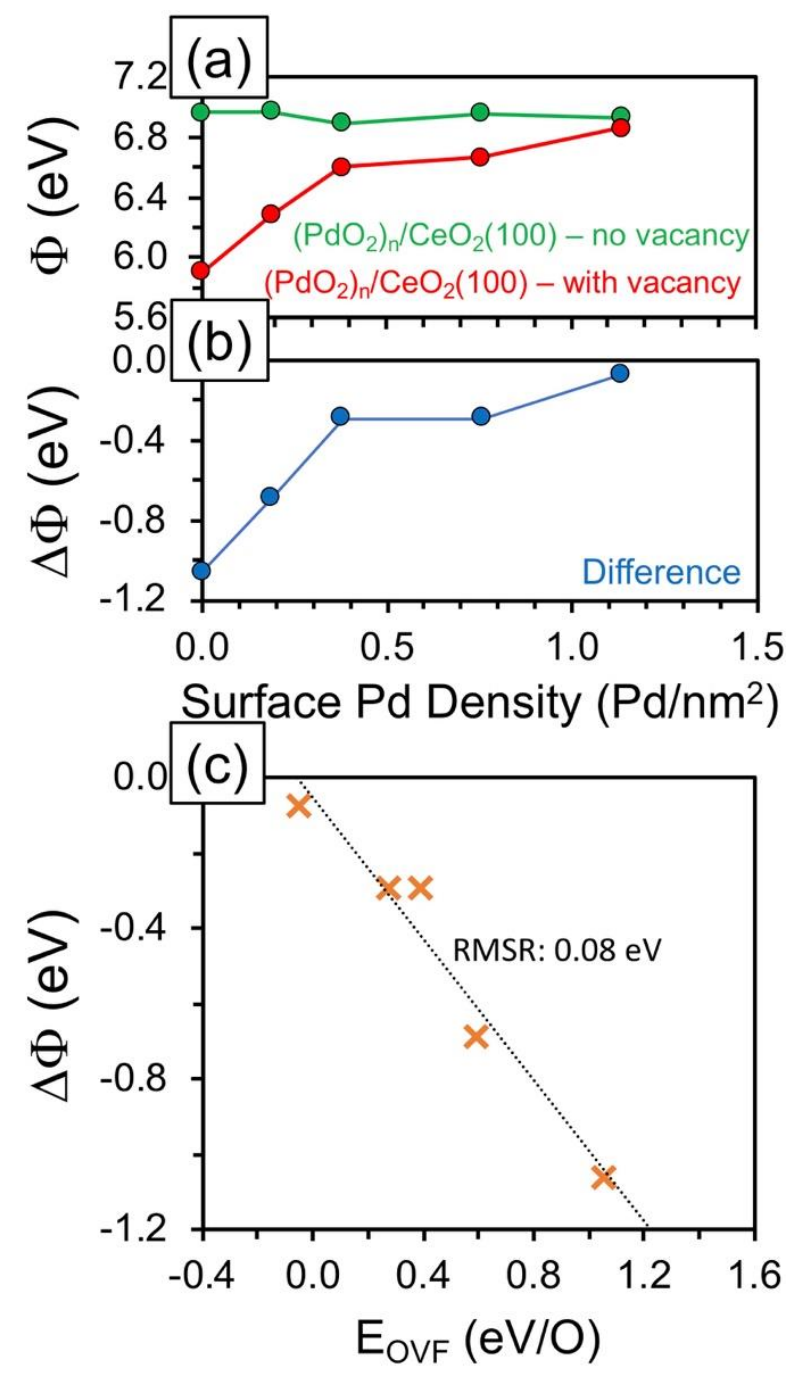

Figure S19. (a) Computed work functions $(\Phi)$ for the $\mathrm{Pd}$-doped $\mathrm{CeO}_{2}(100)$ surface with (red line) and without (green line) $\mathrm{O}$ vacancies as a function of surface $\mathrm{Pd}$ density. Here, the $\mathrm{O}$ atom labeled $\mathrm{O} 3$ in Figure 5 of the main text was removed to form the $O$ vacancy. (b) Work function change $(\Delta \Phi)$ as a result of forming this $O$ vacancy. (c) Work function change plotted against the corresponding OFVE, showing excellent correlation between the two quantities. Note that the OVFE has been plotted in units of $\mathrm{eV} / \mathrm{O}$ to more closely match the units of the work function. 


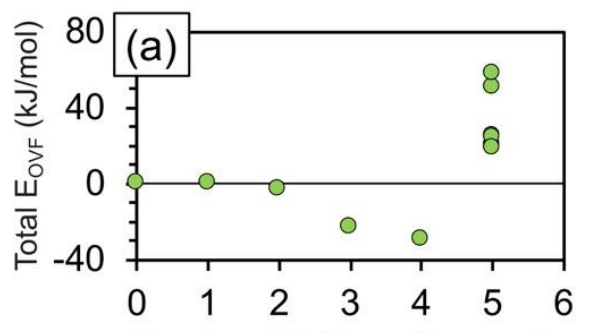

Number of O Atoms Removed

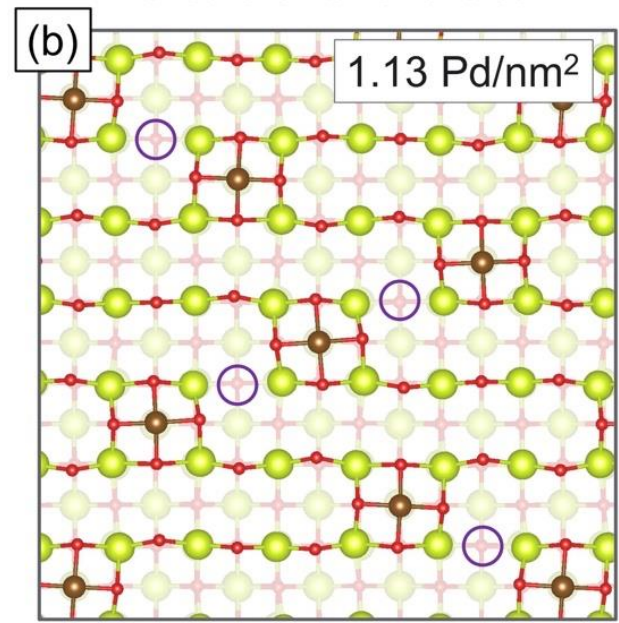

Figure S20. (a) total OVFE (extensive property) as a function of the number of $O$ atoms removed from the $1.13 \mathrm{Pd} / \mathrm{nm}^{2}$ model. (b) $1.13 \mathrm{Pd} / \mathrm{nm}^{2}$ model after exothermic removal of $4 \mathrm{O}$ total $\mathrm{O}$ atoms. Color scheme is identical to that used in Figure $\mathrm{S} 12$.

In Figure S20, we computed the total OVFE as:

$$
\mathrm{E}_{\mathrm{OVF}, \text { tot }}\left[\mathrm{N}_{\mathrm{O}}\right]=\mathrm{E}_{\text {total }}\left[\mathrm{N}_{\mathrm{O}}\right]-\mathrm{E}_{\text {total }}[0]+\mathrm{N}_{\mathrm{O}}\left(\frac{1}{2} \mathrm{E}_{\mathrm{O}_{2}(\mathrm{~g})}\right)
$$

where $E_{\text {total }}\left[\mathrm{N}_{\mathrm{O}}\right]$ is the total DFT energy of the $(6 \times 6) \mathrm{Pd} / \mathrm{CeO}_{2}(100)$ supercell wherein $\mathrm{N}_{\mathrm{O}}$ oxygen atoms have been removed, and $\mathrm{E}_{\mathrm{O}_{2}(\mathrm{~g})}$ is the DFT calculated energy of an $\mathrm{O}_{2}$ molecule in the gas phase. 